Institute for Research on Poverty

Discussion Paper no. 1361-09

\title{
The Impact of Family Income on Child Achievement: Evidence from the Earned Income Tax Credit
}

\author{
Gordon Dahl \\ University of California, San Diego and NBER \\ E-mail: gdahl@ucsd.edu \\ Lance Lochner \\ University of Western Ontario and NBER \\ E-mail: 1lochner@uwo.ca
}

January 2009

We thank Mark Bils, Dan Black, David Blau, Julie Cullen, David Dahl, Greg Duncan, Rick Hanushek, Shakeeb Khan, Robert Moffitt, Krishna Pendakur, Uta Schoenberg, Todd Stinebrickner, Chris Taber, Mo Xiao and three anonymous referees for helpful comments. We also thank seminar participants at Brigham Young University, UC Berkeley, University of Chicago GSB, Institute for Fiscal Studies, Federal Reserve Bank of Cleveland, University of Kentucky, LSE, Northwestern University, University of Toronto, University of Waterloo, and Wilfred Laurier University, and conference participants at the 2005 Institute for Research on Poverty Summer Workshop, 2005 Canadian Econometrics Study Group Meeting, 2005 NBER Summer Institute, 2008 RCEA LaborWorkshop. Philippe Belley, Javier Cano Urbina, Marina Renzo, and Fernando Leiva provided excellent research assistance. Both authors gratefully acknowledge financial support from the William T. Grant Foundation. Lochner also acknowledges support from the Social Sciences and Humanities Research Council of Canada.

IRP Publications (discussion papers, special reports, and the newsletter Focus) are available on the Internet. The IRP Web site can be accessed at the following address: http://www.irp.wisc.edu 


\begin{abstract}
Past estimates of the effect of family income on child development have often been plagued by endogeneity and measurement error. In this paper, we use two simulated instrumental variables strategies to estimate the causal effect of income on children's math and reading achievement. Our identification derives from the large, non-linear changes in the Earned Income Tax Credit (EITC) over the last two decades. The largest of these changes increased family income by as much as 20 percent, or approximately $\$ 2,100$. Using a panel of almost 5,000 children matched to their mothers from National Longitudinal Survey of Youth datasets allows us to address problems associated with unobserved heterogeneity, endogenous transitory income shocks, and measurement error in income. Our baseline estimates imply that a $\$ 1,000$ increase in income raises combined math and reading test scores by 6 percent of a standard deviation in the short run. The gains are larger for children from disadvantaged families and are robust to a variety of alternative specifications. We find little evidence of long-run income effects, with most of the effects disappearing after one year.
\end{abstract}




\section{Introduction}

In 2003, 12.9 million children in the U.S. under the age of 18, or more than one in six children, were living in poverty (U.S. Census Bureau, 2004). Given such a high poverty rate, the consequences of growing up poor on child well-being and future success has emerged as an important research topic. Of particular interest is whether income support programs like the Earned Income Tax Credit (EITC) can improve child development. However, the extent to which income maintenance programs, and family income more generally, impact children is not easily estimated.

The major challenge faced by researchers attempting to estimate the causal effect of family income on children's outcomes has been the endogeneity of income. Children growing up in poor families are likely to have adverse home environments or face other challenges which would continue to affect their development even if family income were to increase substantially. Furthermore, yearto-year changes in family circumstances like parental job loss or promotion, illness, or moving to a new neighborhood may affect both family income as well as family dynamics and parenting behavior. The latter poses a problem for traditional empirical studies that fail to separately identify the effects caused by changes in income from the effects of changes in other unmeasured family circumstances. These concerns have prevented the literature from reaching a consensus on whether family income has a causal effect on child development (see Duncan and Brooks-Gunn (1997), Haveman and Wolfe (1995), Mayer (1997)).

Since the mid-1990s, one of the largest federal anti-poverty programs in the U.S. has been the EITC, which provides cash assistance to low-income families and individuals who have earnings from work. ${ }^{1}$ Low income families with two or more children can receive a credit of up to $40 \%$ of their income in recent years (up to $\$ 4,204$ in 2003), while families with one child can receive a credit of up to $34 \%$. In 2003 , the EITC provided $\$ 37.5$ billion in income benefits to 20.8 million families and individuals, lifting more children out of poverty than any other government program (Center on Budget and Policy Priorities, 2005). It is natural to ask what effect the EITC and other income maintenance programs have on disadvantaged children.

Expansions of the EITC in the late 1980s and 1990s provide an exogenous source of income variation for American families that we use to identify the effects of family income on child achievement. Figure 1 shows that EITC expansions over this period were sizeable and primarily benefitted low to middle income families. ${ }^{2}$ Not only did the maximum benefit amount increase substantially,

\footnotetext{
${ }^{1}$ See Hotz and Scholz (2003) and Eissa and Hoynes (2005) for detailed descriptions of the EITC program and a summary of related research.

${ }^{2}$ The general tax schedule changed very little between 1987 and 1999 . We analyze this period in order to focus on
} 
but the range of family income which qualified families for EITC benefits also expanded. The figure shows that two-child families with pre-tax incomes ranging from $\$ 12,000-16,000$ would have seen their EITC payments increase by as much as $\$ 900$ from 1987 to 1993 and another $\$ 2,100$ between 1993 and 1997. ${ }^{3}$ The maximum subsidy rate for low income families with two children doubled from $19.5 \%$ to $40 \%$ of earned income over the latter period. ${ }^{4}$

We estimate the impact of changes in family income (resulting from the EITC expansions) on child cognitive achievement. Our estimation strategy is based on the fact that low to middle income families benefitted substantially from expansions of the EITC in the late-1980s and mid-1990s while higher income families did not. To the extent that income affects child achievement, we should observe relative improvements in the test scores of children from families benefitting the most from the EITC expansions.

Our analysis uses panel data on almost 5,000 children matched to their mothers in the Children of the National Longitudinal Survey of Youth (NLSY). These data contain a rich set of income and demographic measures. More importantly, these data have up to five repeated measures of cognitive test scores per child taken every other year, which allows us to account for unobserved child fixed effects.

Our instrumental variables estimates suggest that current income has a significant effect on a child's math and reading achievement — a $\$ 1,000$ increase in family income raises math and reading test scores by about $6 \%$ of a standard deviation. The estimated effects are larger for young children and for those from more disadvantaged backgrounds. However, our estimates also suggest that these effects are short-lived, largely disappearing after one year (unless higher income levels are maintained). ${ }^{5}$

While modest, our instrumental variable estimates are larger than cross-section ordinary least squares (OLS) or standard fixed effects (FE) estimates. Several explanations may account for this

poor families and the impact of the EITC expansions. Even though data for 1985 is available in our NLSY dataset, we omit it since the Tax Reform Act of 1986 introduced several changes to the tax code.

${ }^{3}$ All dollar amounts are reported in year 2000 dollars, using the Consumer Price Index for all Urban Consumers (CPI-U) to adjust for inflation. The Tax Reform Act of 1986 began to adjust maximum credit amounts and phasein/phase-out regions for cost-of-living changes in years that did not specifically legislate changes in the EITC schedule. However, the federal tax adjustment is based on the CPI from the previous year (rather than the current year as used in our calculations). This explains why the reported maximum credit is about $\$ 30$ less in 1989 than it was in 1987 in our figures.

${ }^{4}$ Expansions for single child families were quite similar to those for two-child families prior to 1993; however, they have been more modest since. While their phase-in subsidy rate nearly doubled from $18.5 \%$ to $34 \%$ between 1993 and 1997, their maximum credit amount 'only' increased by about $50 \%$. Only $10 \%$ of the observations used in our analysis are from families with only one child.

${ }^{5} \mathrm{~A}$ number of recent studies estimate similarly strong fade-out effects for the 'value added' of individual teachers on student test scores (e.g. Lockwood, et al. 2007, Jacob, Lefgren and Sims 2008, and Rothstein 2008). 
difference. One is that income is noisily measured, so that OLS and FE estimates suffer from attenuation bias. It is also possible that income matters more for the most disadvantaged and that our instrument largely reflects the effect of income for these families. Perhaps the most interesting explanation is that expectations about future income play an important role in determining child outcomes. In this case, permanent changes in family income should have larger effects on children than do temporary changes. To the extent that changes in the EITC are expected to last longer than most idiosyncratic shocks to family income, our instrumental variable estimates should be greater than traditional OLS and fixed effect estimates.

This paper proceeds as follows. In the next section, we give a brief literature review. Section 3 discusses our strategy for estimating the effect of family income on child outcomes. We then discuss the data and document the large changes in the EITC in Section 4. Section 5 presents estimates of the effect of income on math and reading test scores, including results from a variety of alternative specifications and robustness checks. Section 6 concludes.

\section{Previous Research}

A growing empirical literature questions how poverty affects a child's well-being and whether income support programs can improve a child's life chances. However, evidence on the extent to which family income affects child development is mixed. Previous studies differ in data, methods, and findings, as discussed in the collection of studies in Duncan and Brooks-Gunn (1997) or the surveys in Haveman and Wolfe (1995) and Mayer (1997).

Researchers have provided several explanations for why family income might affect child development. First, poverty is associated with increased levels of parental stress, depression, and poor health - conditions which might adversely affect parents' ability to nurture their children (see, e.g., McLoyd 1990). For example, in 1998, $27 \%$ of kindergartners living in poverty had a parent at risk for depression, compared to $14 \%$ for other kindergartners (Child Trends and Center for Child Health Research, 2004). Low income parents also report a higher level of frustration and aggravation with their children, and these children are more likely to have poor verbal development and exhibit higher levels of distractability and hostility in the classroom (Parker et. al, 1999). Extra family income might also matter if parents use the money for child-centered goods like books, for quality daycare or preschool programs, for better dependent health care, or to move to a better neighborhood. ${ }^{6}$

\footnotetext{
${ }^{6}$ Low income parents have fewer children's books in their homes and spend less time reading to their children, markers which are negatively associated with future academic performance. Children in poor families are also less
} 
Until recently, empirical studies linking poverty and income to child outcomes have done little to eliminate biases caused by the omission of unobserved family and child characteristics. Most studies employ regressions of an outcome variable (such as scholastic achievement) on some measure of family income and a set of observable family, child, and neighborhood characteristics. While these studies reveal the correlations between income and child outcomes, they do not necessarily estimate a causal relationship as Mayer (1997), Duncan and Brooks-Gunn (1997), and others have pointed out. Children living in poor families may have a worse home environment or other characteristics that the researcher does not observe. These omitted variables may be part of the reason for substandard achievement and may continue to affect children's development even if family income were to rise.

Blau (1999), Duncan, et. al (1998), and Levy and Duncan (1999) use fixed effects estimation strategies to eliminate biases caused by permanent family or child characteristics. All three studies use differences in family income levels across siblings to remove fixed family factors when estimating the impacts of income on child outcomes. Using PSID data, both Duncan, et. al (1998) and Levy and Duncan (1999) find that family income at early ages is more important for determining educational attainment whether they control for fixed family effects or not. Using data from the Children of the NLSY, Blau (1999) reaches somewhat different conclusions. He estimates larger effects of "permanent income" when he controls for "grandparent fixed effects" (i.e. comparing outcomes for the children of sisters) than when he does not. However, he finds smaller and insignificant effects of current family income on achievement and behavioral outcomes when he uses fixed effect strategies (regardless of whether he uses comparisons of cousins, siblings, or repeated observations for the same individual) rather than OLS. While these studies represent a significant step forward, they do not control for endogenous transitory shocks (e.g. parental job loss or promotion, family illness, residential moves) and likely suffer from severe attenuation bias, since growth in income is typically noisily measured. ${ }^{7}$

Another line of research uses data from welfare and anti-poverty experiments conducted during the 1990s. Except for a recent working paper by Duncan, Morris and Rodrigues (2007), these studies focus on program impacts, but do not separate out the effects of family income from other

likely to receive adequate health care and nutrition, both of which might affect performance in school. Finally, neighborhood poverty has been associated with underfunded public schools and lower achievement scores among young children (Child Trends and Center for Child Health Research, 2004).

${ }^{7}$ Taking a slightly different approach, Carniero and Heckman (2002) estimate the effects of income at different child ages on subsequent college enrollment, controlling for the present discounted value of family income (a measure of "permanent income") and math test scores at age twelve. While they estimate significant effects of "permanent income", the estimated effects of income at early childhood ages and at later childhood ages are insignificant. 
aspects of the programs. Duncan, Morris and Rodrigues (2007) combine data from ten of these experiments in an attempt to separately estimate the effect of family income from employment and welfare effects induced by the programs. They find a modest effect of family income on school achievement for young children that is consistent with our estimates.

The different conclusions reached by recent studies suggest that unobserved heterogeneity and endogenous income shocks are important concerns. In the following section, we outline two simulated instrumental variables strategies which eliminate omitted variable biases due to both permanent and temporary shocks correlated with family income. Our approach also helps alleviate any bias due to measurement error in income.

Using our instrumental variables approach, we explore a few simple dynamic specifications of child achievement that allow for lasting effects of family income on children. Few previous studies explore dynamic relationships between family income and child achievement. Those that do tend to focus on the relative importance of family income received at different child ages and are subject to the same concerns about unobserved heterogeneity and endogenous family income shocks as described above. Most of these studies find that income received when a child is young has stronger lasting impacts than does income received during later childhood or adolescence (see Duncan and Brooks-Gunn 1997 and Duncan et al. 1998). ${ }^{8}$

\section{Methodology}

\subsection{Modelling Child Achievement}

Child achievement potentially depends on a child's ability, as well as other past and present child inputs (e.g. parental time, books, neighborhoods, schools, and home environments). ${ }^{9}$ Since family income affects decisions about investment in children, as well as parental stress and whether the general home environment is conducive to development, current and lagged family income have the potential to affect child outcomes at any particular age. In this section, we model how changes in family income (through such policies as the EITC) affect child achievement.

Let $x_{i}$ reflect observable permanent characteristics and $\mu_{i}$ reflect unobserved permanent 'ability'

\footnotetext{
${ }^{8}$ Related studies estimate dynamic models of child development as a function of family and school inputs; however, they do not directly measure the effects of family income on children. For example, Todd and Wolpin (2007) estimate a dynamic model of both family and school inputs into child development. Their estimates imply strong lasting effects of family inputs (e.g. number of books in the home) but relatively weak effects of measured school inputs (e.g. teacher salary). Building on the 'value added' literature aimed at estimating the effectiveness of individual teachers, a number of recent studies find that teacher-induced gains in student test scores are sizeable in the short-run, but they tend to fade out very quickly (Lockwood, et al. 2007, Jacob, Lefgren and Sims 2008, and Rothstein 2008).

${ }^{9}$ See Todd and Wolpin (2003) for a clear exposition of the issues involved in identifying and estimating child achievement production functions.
} 
for child $i$. These measures can also incorporate unobserved long-run differences across families. Let $w_{i a}$ reflect time-varying characteristics and $I_{i a}$ total family income (net of any taxes and transfers, including EITC payments) for child $i$ at age $a$. Finally, let $\varepsilon_{i a}$ denote any time varying unobserved shocks to the child or family. Using this notation, a general model for child outcome $y_{i a}$ as a function of the child's family characteristics and income history is $y_{i a}=f_{a}\left(x_{i}, w_{i 0}, \ldots, w_{i a}, I_{i 0}, \ldots, I_{i a}, \mu_{i}, \varepsilon_{i a}\right) .{ }^{10}$ For empirical purposes, it is useful to simplify the child outcome equation as follows:

$$
y_{i a}=x_{i}^{\prime} \alpha_{a}+w_{i a}^{\prime} \beta+I_{i a} \delta_{0}+I_{i, a-1} \delta_{1}+\ldots+I_{i, a-L} \delta_{L}+\mu_{i}+\varepsilon_{i a},
$$

assuming that the effects of income on child achievement last for $L$ years. ${ }^{11}$

To focus on the role of income, equation (1) abstracts from the effects of past time-varying characteristics; however, these can easily be incorporated in the same way as past income. Equation (1) also abstracts from the possibility that income has different effects at different ages (i.e. effects depend only on the time elapsed between when income is earned and when child achievement is measured) or at different points in the income distribution (i.e. linearity in income is assumed). We explore these issues empirically below.

The specification in equation (1) allows for different effects of permanent characteristics at all ages (i.e. $\alpha_{a}$ ). In our empirical analysis, we allow $x_{i}$ characteristics (e.g. race, mother's ability) to affect both the level and growth of child achievement. Taking first-differences of equation (1) to eliminate the unobserved fixed effect $\mu_{i}$ yields:

$$
\Delta y_{i a}=x_{i}^{\prime} \alpha+\Delta w_{i a}^{\prime} \beta+\Delta I_{i a} \delta_{0}+\Delta I_{i, a-1} \delta_{1}+\ldots+\Delta I_{i, a-L} \delta_{L}+\Delta \varepsilon_{i a},
$$

where $\alpha$ is the effect of $x_{i}$ on achievement growth. We empirically estimate this achievement growth equation allowing income to affect child outcomes for several years (sometimes imposing restrictions on the $\delta$ parameters).

The canonical achievement specification in the child development literature assumes that there are only contemporaneous effects of family income on children, ignoring any long-run effects. That is, $L=0$ in equations (1) and (2), which yields the following estimating equation in first-differences:

$$
\Delta y_{i a}=x_{i}^{\prime} \alpha+\Delta w_{i a}^{\prime} \beta+\Delta I_{i a} \delta_{0}+\Delta \varepsilon_{i a} .
$$

\footnotetext{
${ }^{10}$ Permanent income theory suggests that expectations about future income are also likely to affect children as well, an issue we return to below.

${ }^{11}$ One commonly used achievement model assumes that current achievement depends on current income and lagged achievement (e.g. $y_{i a}=x_{i}^{\prime} \alpha_{a}+w_{i a} \beta+I_{i a} \delta+y_{i, a-1} \rho+\mu_{i}+\varepsilon_{i a}$ ). Recursively substituting in for lagged values of achievement on the right hand side yields a specification very similar to equation (1) in which all lagged income measures and other time varying characteristics would also be included.
} 
This 'contemporaneous effects' model serves as our baseline and receives empirical support in our analysis.

Finally, we consider an alternative extreme in which income has permanent effects on child outcomes. To distinguish between long- and short-term effects of income in a parsimonious way, we allow current income to have a different effect from past income but we assume all past income has the same effect on child outcomes:

$$
y_{i a}=x_{i}^{\prime} \alpha_{a}+w_{i a} \beta+I_{i a} \delta_{0}+\left(I_{i, a-1}+\ldots+I_{i, 0}\right) \delta_{1}+\mu_{i}+\varepsilon_{i a}
$$

Taking first-differences yields:

$$
\Delta y_{i a}=x_{i}^{\prime} \alpha+\Delta w_{i a}^{\prime} \beta+\Delta I_{i a} \omega+I_{i a} \delta_{1}+\Delta \varepsilon_{i a}
$$

where $\omega=\delta_{0}-\delta_{1}$ reflects the added short-term effect of income on contemporaneous child outcomes above the long-run effect it has on future outcomes. As a practical matter, this specification simply adds current income to the first-differenced 'contemporaneous effects' model of equation (3).

\subsection{Using Changes in the EITC to Estimate the Effects of Income}

The primary concern with least squares estimation of the models above is the possibility that changes in unobserved factors affecting child development (i.e. $\Delta \varepsilon_{i a}$ ) are correlated with changes in family income. More generally, $\Delta \varepsilon_{i a}$ may be correlated with the entire history of income levels given the strong intertemporal correlation of income and its tendency for regression to the mean. To address this problem, we employ two related IV estimation strategies that take advantage of major changes in the EITC to estimate the effects of income on children. To simplify the discussion, we focus on the 'contemporaneous effects' model of equation (3); however, we take a similar approach in estimating the more general models of equations (2) and (5), which allow for long-term effects of income on children. ${ }^{12}$

We use total net family income (inclusive of EITC payments and net of other federal and state taxes and transfers) as our measure of total family income, $I_{i a}$. EITC income, $\chi_{a}^{s_{i a}}\left(P_{i a}\right)$, is a function of pre-tax income, $P_{i a}$, for the year when child $i$ is age $a$. We also take into account other taxes, $\tau_{a}^{s_{i a}}\left(P_{i a}\right)$. The superscript $s_{i a}$ on the EITC and tax functions denotes which schedule a child's family is on; the EITC schedules only differ based the number of children in the household,

\footnotetext{
${ }^{12}$ Estimating more general first-difference models with lagged changes in income or income in levels like those of equations (2) or (5) requires additional instruments for each new income term. We use instruments analogous to those described in this section. See Appendix A for details.
} 
while the more general tax function depends on a broader set of family characteristics. ${ }^{13}$ Therefore, total net family income is given by

$$
I_{i a}=P_{i a}+\chi_{a}^{s_{i a}}\left(P_{i a}\right)-\tau_{a}^{s_{i a}}\left(P_{i a}\right) .
$$

Central to our analysis is the variation in EITC schedules over time and the way in which EITC expansions have differentially augmented the incomes of different families.

Simulated Instrumental Variables. Our first estimation approach follows the 'simulated instrumental variable' (SIV) strategy used by Gruber and Saez (2002). ${ }^{14}$ This strategy begins by assuming that changes in the EITC structure are independent of idiosyncratic family circumstances. To exploit this, as an instrument for $\Delta I_{i a}$ in estimating equation (3), we use

$$
\Delta \chi_{a}^{S I V} \equiv \chi_{a}^{s_{i, a-1}}\left(P_{i, a-1}\right)-\chi_{a-1}^{s_{i, a-1}}\left(P_{i, a-1}\right)
$$

This instrument puts lagged pre-tax income through both the current and lagged EITC schedules to calculate a family's predicted change in EITC income. In other words, it reflects the change in EITC payment from age $a-1$ to $a$ that would be received by family $i$ if their pre-tax income remained constant at the age $a-1$ value. Thus, it only reflects changes in the EITC structure and not other changes in family income that might be correlated with $\Delta \varepsilon_{i a}$.

Of course, simply estimating equation (3) using $\Delta \chi_{a}^{S I V}$ as an instrument is still likely to yield biased estimates for $\delta_{0}$, since changes in families' simulated EITC payments are a function of age $a-1$ pre-tax family income $\left(P_{i, a-1}\right)$, which is likely to be correlated with the subsequent change in income due to such factors as measurement error, regression to the mean, and any serial correlation in income shocks. ${ }^{15}$ Therefore, similar to Gruber and Saez (2002), we augment the outcome equation with a flexible function of $P_{i, a-1}$ when instrumenting. Letting $\Phi\left(P_{i, a-1}\right)$ reflect a flexible polynomial of lagged pre-tax income, SIV estimates

$$
\Delta y_{i a}=x_{i}^{\prime} \alpha+\Delta w_{i a}^{\prime} \beta+\Delta I_{i a} \delta_{0}+\Phi\left(P_{i, a-1}\right)+\eta_{i a}
$$

\footnotetext{
${ }^{13}$ Actual EITC schedules distinguish between earned and unearned income. For our sample period, federal EITC schedules only differ based on whether there is one or more than one child in the household. (Starting in 2002, the flat and phase-out regions expanded for married versus single filers.) Other taxes depend on the number of children as well as marital status. While our empirical analysis takes these distinctions into account, we ignore them here for expositional purposes. The empirical analysis also includes non-taxable income sources in total family income. Finally, the empirical analysis also includes state taxes and transfers when constructing total family income, although we only use changes in the federal EITC schedule to construct our baseline instruments. We add in state EITCs in a robustness table. See Appendix A for further details.

${ }^{14}$ This strategy builds on Feldstein (1995) and Currie and Gruber (1996), who use the effects of policy changes on economy-wide aggregates rather than the distributional consequences of policy changes to identify their parameters of interest. See Moffitt and Wilhelm (2000) for a general discussion of the SIV methodology and its application.

${ }^{15}$ Clearly, using the actual change in EITC income for child $i, \chi_{a}^{s_{i, a}}\left(P_{i, a}\right)-\chi_{a-1}^{s_{i, a-1}}\left(P_{i, a-1}\right)$, as an instrument would be problematic, since it directly depends on pre-tax income levels in both periods - the very source of concerns about endogeneity.
} 
using $\Delta \chi_{a}^{S I V}$ as an instrument for $\Delta I_{i a}$. One can think of the polynomial $\Phi\left(P_{i, a-1}\right)$ as a control function, which implicitly equals $E\left[\Delta \varepsilon_{i a} \mid P_{i, a-1}, x_{i}, \Delta w_{i a}\right] .{ }^{16}$

There are two fundamental assumptions of this approach: (i) the control function $\Phi(\cdot)$ must be flexible enough to capture the true expected relationship between child development shocks and lagged pre-tax income, and (ii) this relationship must be stable over time. If the income process is highly non-stationary (specifically, if the joint density of $P_{i a}$ and $P_{i, a-1}$ changes over time), the latter is not likely to hold. Furthermore, if the evolution of income over time differs systematically with $x_{i}$ or $\Delta w_{i a}$ (an obvious concern if changes in parental marital status are included in $\Delta w_{i a}$ ) or if the relationship between $\Delta \varepsilon_{i a}$ and pre-tax income depends on $x_{i}$ or $\Delta w_{i a}$, then the control function should be generalized to account for these relationships. ${ }^{17}$ To address these issues, we explore the robustness of our SIV estimates to different assumptions about the control function. Finally, note that this method requires at least three periods of data, since we need independent variation in the EITC schedule over time given a flexible control function.

Projection-based SIV. Our second IV strategy uses a projection of $P_{i, a-1}$ onto an exogenous set of variables $z_{i}$ (rather than $P_{i, a-1}$ itself) to determine how EITC expansions benefitted different families. More specifically, we first estimate $\hat{P}_{i, a-1}\left(z_{i}\right)=z_{i} \hat{\gamma}_{a-1}$ by regressing pre-tax income on $z_{i}$; then, we use $\Delta \chi_{a}^{P S I V} \equiv \chi_{a}^{s_{i, a-1}}\left(\hat{P}_{i, a-1}\right)-\chi_{a-1}^{s_{i, a-1}}\left(\hat{P}_{i, a-1}\right)$ as an instrument for $\Delta I_{i a}$ in estimating equation (3). ${ }^{18}$ We refer to this method below as Projection-based Simulated IV (PSIV). If $E\left(\Delta \varepsilon_{i a} \mid z_{i}\right)=0$, then this approach produces consistent estimates without the need for a control function as in SIV. The key difference is that while $P_{i, a-1}$ is likely to be correlated with $\Delta \varepsilon_{i a}$, $\hat{P}_{i, a-1}$ is not by construction. We use $z_{i}$ variables that are a subset of $x_{i}$ and do not assume that we observe any special variables that affect family income but not child development. ${ }^{19}$

Identification does not rely on assumptions about the direct relationship between $y_{i a}$ and $z_{i} \subseteq x_{i}$ in the achievement equation, but we need at least three periods of data. The key identifying assumption is that the direct relationship between $z_{i}$ characteristics and child outcomes is stable over time, but the relationship between $z_{i}$ characteristics and family income is changing due to

\footnotetext{
${ }^{16}$ See Heckman and Robb (1985) for a general treatment of control functions.

${ }^{17}$ In this case, the more general control function $\Phi\left(P_{i, a-1}, x_{i}, \Delta w_{i a}\right)$ should replace $\Phi\left(P_{i, a-1}\right)$ in equation (6). See Appendix A for a more detailed discussion of these issues.

${ }^{18}$ This approach is closely related to the 'grouping estimators' discussed in Blundell, Duncan, and Meghir (1998). For a single binary $z_{i}$, our approach is equivalent to separating the sample into two groups based on $z_{i}$ and dividing the difference-in-difference estimated effect of the EITC on test scores by the difference-in-difference estimated effect of the EITC on total family income.

${ }^{19}$ In practice, we use mother's age as well as time invariant characteristics (e.g. mother's ability as measured by the AFQT, race, and educational attainment as of an early adult age), none of which can respond to time varying shocks affecting child development or to changes in the EITC schedule. All of these variables are included in the child achievement equation.
} 
changes in the EITC structure. On average, some types of families (e.g. black families or those with less educated mothers) receive large increases in their incomes when the EITC expands while others (e.g. white families or those with highly educated mothers) do not. If income matters, it should raise the test scores for those types of families who benefit from the EITC expansions relative to those that do not. ${ }^{20}$

Two minor practical issues arise in our analysis. First, the vast majority of EITC recipients receive their credit after filing their taxes the following year. Therefore, we link test scores (typically measured sometime between March and December in our data) with income earned in the previous calendar year (reported during the same survey as test scores are recorded), referring to them as 'contemporaneous'. Second, we only observe child achievement scores every other year as we discuss further below. Thus, we use two-year differences rather than one-year differences in our analysis. Appendix A briefly describes how this affects the estimating equations above.

\section{Data}

We use data from the Children of the NLSY and the main NLSY sample of mothers. These data are ideal for studying the effects of family income on children for several reasons. First, we can link children to their mothers, and second, we can follow families over time. Third, the NLSY contains repeated measures of various child outcomes and comprehensive measures of family income. Finally, the NLSY oversamples poor and minority families, which provides a larger sample of families eligible for the EITC. ${ }^{21}$

The NLSY collects a rich set of variables for both children and mothers repeatedly over time. For children, biannual measures of family background and cognitive achievement are available from 1986 to 2000. Detailed longitudinal demographic, educational, and labor market information for the mothers is available annually from 1979 through 1994 and biannually thereafter. Equally important, family income measures (for the previous calendar year) are available in all survey years for the mothers up to 1994 and biannually thereafter. ${ }^{22}$ Hence, for children born after 1979, we can compile an income history for almost every year since birth. While the NLSY contains a broad

\footnotetext{
${ }^{20}$ It is important to note that by including all $z_{i}$ factors in the differenced child outcome equation (3), we allow for the possibility that children from different types of families have different growth rates in test scores. We do not, therefore, assume that test scores grow at the same rate in low/high education or black/white families.

${ }^{21}$ The poor white oversample is selected based on the 1978 parental income of NLSY mothers (i.e. the income of grandparents of our sample of children). The NLSY also contains an oversample of military families, which we exclude from our analysis.

${ }^{22}$ The survey reports many components of family income, which we aggregate into three categories of pre-tax/EITC income: earned income, unearned income, and non-taxable income. See Appendix B for a description of these income categories and how we impute missing observations.
} 
array of income questions, it does not ask an individual how much they received in EITC payments or paid in taxes. ${ }^{23}$ Therefore, we impute a family's federal EITC payment and tax burden using the TAXSIM program (version 8) maintained by Daniel Feenberg and the NBER (see Feenberg and Coutts, 1993 and http://www.nber.org/taxsim). One of the main benefits of the panel is that we can estimate models that account for child fixed effects.

In our analysis, we focus on measures of scholastic achievement in math and reading based on standardized scores on Peabody Individual Achievement Tests (PIAT). The assessments measure ability in mathematics, oral reading and word recognition ability (reading recognition), and the ability to derive meaning from printed words (reading comprehension). From 1986 to 2000, the tests were administered biannually to children five to fifteen years old. Children took each individual test at most five times due to the age restrictions.

To make the PIAT test scores more easily interpretable, we create normalized test scores with a mean of zero and a standard deviation of one based on the random sample of test takers (i.e. excluding the poor and minority oversamples). We also create a combined math-reading score, which takes the average of our normalized math and reading scores. This is then re-normalized to have a mean of zero and standard deviation of one in the random sample. ${ }^{24}$ Our full sample that includes oversamples of blacks, hispanics, and poor whites has negative average normalized test scores, since children in the oversamples are more disadvantaged on average.

We restrict our main sample to children observed in survey years after 1988 and with valid PIAT scores, family background characteristics, and family income measures in at least two survey years, since our primary analysis estimates models with child fixed effects. ${ }^{25}$ This sample includes 4,720 interviewed children born to 2,527 interviewed mothers, with children observed 2.4 times on average. Table 1 provides information on family income and EITC eligibility over time for this main sample. The table reveals that median after-tax family income rose in real terms from $\$ 16,207$ reported in 1988 to $\$ 22,615$ reported in 2000 . The time trend in family income, which outpaced inflation, is largely attributable to the aging of mothers in the sample. The relevance of changes in the EITC schedule over time is also evident in Table 1. Roughly $60 \%$ of children live in families which qualify for the EITC, a high rate that is partly due to the original NLSY oversampling of

\footnotetext{
${ }^{23}$ Take-up rates for EITC benefits are high. Both the IRS (2002) and Scholz (1994) estimate that roughly 80 to 87 percent of eligible households receive the credit.

${ }^{24}$ As discussed in NLSY79 User's Guide, the initial standardized test scores we begin with are already normalized by child age to have a mean of 100 and a standard deviation of 15 . Thus, our re-normalized test score distributions are nearly identical within each age group, having close to a mean of zero and standard deviation of one. See Appendix B for additional details on the PIAT tests and our normalization procedure.

${ }^{25}$ We exclude the 1986 survey year (which records income for 1985) to focus our analysis on changes in the EITC, rather than the large changes in the tax code which resulted from the Tax Reform Act of 1986.
} 
minorities and poor white families. The largest EITC expansion is reflected in the sizeable increase in EITC eligibility and payment amounts from 1994 to 1996. A sizeable jump in EITC eligibility also occurs from 1988 to 1990 (based on earnings for 1987 and 1989) in response to the expansion of the eligible income range in 1988.

Table B1 in Appendix B describes sample characteristics based on EITC eligibility. The variables are categorized according to the way we use them in our analysis. The first set of variables are those used to estimate predicted family earnings for PSIV estimation (i.e. the $z_{i}$ variables) and are also included as controls in our baseline SIV and PSIV specifications. These include exogenous mother characteristics like race, age, educational attainment, AFQT score, foreign born, and lived in a rural area at age 14. We use mother's completed education as of age 23 in our analysis to avoid any potential endogeneity. The next set of variables (child gender, child age, number of children, and changes in marital status) are included as regressors in all of our baseline SIV and PSIV specifications but are not used as $z_{i}$ variables to create predicted family earnings in PSIV. Finally, we report some additional family background characteristics for mothers, followed by a measure of marital status the previous year and mothers' spousal characteristics. These are used as additional controls in a robustness check and for a preliminary set of OLS estimates.

Column (i) provides summary statistics for our full sample. Over half the sample is black or hispanic due to the oversampling of minorities. The average age of mothers is 34 years old, although the youngest mother with a child in our sample is 25. Columns (ii) and (iii) in Table B1 break down the summary statistics based on EITC eligibility, while column (iv) reports the difference between eligible and ineligible families. Children from EITC eligible families (relative to those that are ineligible) are more likely to be minorities and have mothers with less education and lower AFQT scores. Their parents are also less likely to be married. These differences suggest that some children will be more directly affected by changes in the generosity of the EITC (e.g. black children with unmarried, low educated mothers versus white children with married, highly educated mothers).

\section{The Effect of Income on Cognitive Achievement}

In this section, we discuss the estimated impact of family income on children's math and reading achievement. We first report standard OLS and differenced estimates of outcome equation (1) under different assumptions about the dynamic effects of income. We also briefly discuss estimates for a few additional specifications previously employed in the literature. We then turn to our main SIV and PSIV estimation strategies, which account for measurement error, permanent unobserved 
heterogeneity, and temporary unobserved shocks. We explore whether income changes have lasting effects on child achievement, whether the effects vary across different demographic groups, and whether income differentially affects younger versus older children. To establish the robustness of our findings, we examine a number of different specifications, including regressions which account for time-varying state policies, more general control functions, and maternal labor market participation.

\subsection{OLS and Differenced Estimates}

We begin by presenting OLS and differenced estimates of the effects of family income on our combined math-reading measure of cognitive achievement. As a reminder, the differenced estimates are based on two-year differences, since children are only administered the PIAT tests every other year. The estimates are based on larger sample sizes than most past studies (e.g. Blau 1999) and are, therefore, more precise. More importantly, we estimate more general models of child achievement than most studies, exploring whether income has lasting effects on children. In doing so, we control for all of the variables reported in Table B1 plus a time trend (for level models) and allow growth rates to depend on the variables listed in panels A and B of Table B1 (for differenced models).

Panel A of Table 2 reports estimates of equation (1) under different assumptions about the persistence of income effects. Column (i) assumes the 'contemporaneous effects' model used by most previous studies. Estimated in levels, we find that a $\$ 10,000$ increase in family income raises math-reading test scores by 0.04 standard deviations. Estimated in differences, the effect is less than one-third as large and no longer significant. ${ }^{26}$ There are two reasons to expect a discrepancy between difference (or fixed effects) and cross-sectional OLS estimates. First, measurement error is greater for income measured in differences than in levels, so attenuation bias will be greater for difference estimators. Second, a correlation between unobserved fixed effects and family income will bias cross-sectional OLS estimates. The first bias is greater for difference estimates while the second only affects cross-sectional OLS, so there is no a priori reason to prefer one type of estimator over the other. More importantly, both approaches suffer from additional bias if unobserved transitory shocks to families and children are correlated with family income.

Columns (ii) and (iii) of Panel A estimate more general models that allow for the possibility that income effects persist for up to two years. Interestingly, these estimates suggest that the effects of income fade very quickly over time (within a year): estimates for $\delta_{1}$ and $\delta_{2}$ are both very small and insignificantly different from zero. The estimated contemporaneous effect of income $\left(\delta_{0}\right)$ is quite similar to that of column (i).

\footnotetext{
${ }^{26}$ These estimates are quite similar to the corresponding estimates in Blau (1999).
} 
Panel B of Table 2 explores our second dynamic model of family income and child achievement (equations 4 and 5), which assumes income has a permanent effect on child achievement levels. Estimates in column (i) restrict the full effect of family income to be permanent, while estimates in column (ii) allow for a permanent effect as well as an additional contemporaneous effect. Estimates in column (i) suggest that the permanent effects of income on child achievement are quite small: a one-year increase in income of $\$ 10,000$ permanently raises test scores by less than one-hundredth of a standard deviation. Of course, the effects of a permanent change in income would accumulate over time and become more noticeable after 5-10 years. The specification estimated in column (ii) allows for different effects of income on contemporaneous test scores from the lasting effect on future test scores. The lasting or permanent effect, $\delta_{1}$, is quite small when estimated in levels or differences. The additional effect of income on contemporaneous test scores (on top of its permanent effect) is also quite small and more imprecisely estimated. In general, these specifications suggest that the effects of income are small.

This table highlights the difficulty in separating long- and short-run effects of income due to the high degree of collinearity in earnings. While the level estimates in Panel A imply small (and statistically significant) effects of income on contemporaneous achievement, all of the estimates in Table 2 imply negligible long-run effects of income (with relatively large standard errors).

An alternative specification often seen in the literature regresses child achievement on a longrun average of family income (generally averaging over all available income measures from the past, present, and future). This specification is economically motivated by the standard lifecycle or permanent income model, which assumes family investments in children depend on lifetime or 'permanent' income rather than income in any particular period. Implicit is the assumption that families can borrow and save in order to smooth their consumption and child investments over time. ${ }^{27}$ A separate statistical argument can also be made for regressing child achievement on average income rather than income received in any particular period. Because income is measured with error, standard OLS level and differenced estimators will tend to be biased towards zero, and averaging may alleviate this problem. In practice, previous studies tend to estimate larger effects of average income than of current income (e.g. Blau 1999). We find the same pattern: the relationship between long-run average income and test scores is roughly twice as strong as the relationship between current income and achievement. ${ }^{28}$ One concern with using average long-run

\footnotetext{
${ }^{27}$ It is worth noting that a much more complicated relationship between child investments and income received in the past, present, and future arises when families are uncertain about future income. In this case, test scores are unlikely to be a simple function of income averaged over all periods.

${ }^{28}$ Estimating a specification analogous to column (i) in Panel A.1 of Table 2, we find that a $\$ 10,000$ increase in
} 
family income is the difficulty in accounting for unobserved long-run heterogeneity using fixed effects strategies. Since average family income is likely to be more strongly correlated with unobserved family characteristics than is income for any particular period, estimates using long-run averages of family income may be subject to greater omitted variable bias. ${ }^{29}$

\subsection{SIV and PSIV Estimates}

We now turn to our SIV and PSIV approaches to estimate the effects of family income on child achievement. We begin with our simple 'contemporaneous effects' model in differences (equation 3). Recall from Section 3.2 that we use simulated changes in the EITC (based either on lagged income for SIV or lagged income projected onto exogenous $z_{i}$ characteristics for PSIV) as instruments for changes in actual after-tax/EITC total family income. As a practical matter, identification comes primarily from the substantial expansion of the EITC schedule between 1993 and 1995; however, other smaller changes in the EITC schedule also aid in identification. The approaches reveal whether achievement scores systematically increased more for families who were predicted to receive a greater boost in EITC payments during years when the schedule expanded.

As noted earlier, our SIV approach requires inclusion of a flexible function of lagged pre-tax income as detailed in equation (6). We explored different ordered polynomials and found the estimates to be very similar for all orders above four. To be conservative, we use a sixth order polynomial in lagged pre-tax income as our baseline 'control function'. For PSIV, it is important to include all $z_{i}$ regressors (i.e. the regressors used to project lagged pre-tax income onto before simulating the change in EITC for our instrument) in the main estimating equation. These factors include the mother's race, her age and age-squared, her educational attainment as of age 23, her AFQT score, whether she is foreign born, and whether she lived in a rural area when she was age 14. We also control for the number of children in the household and whether the parents get married or divorced between the two periods when achievement is measured, as these may be important determinants of changes in child achievement. Finally, our baseline specifications also allow for differential growth in achievement based on the child's gender, age, and age-squared. For comparability, we estimate identical specifications for SIV and PSIV, except for the inclusion of the polynomial in lagged pre-tax income for SIV. ${ }^{30}$

average income (averaged over all available years in our data) raises math-reading achievement by 0.079 (standard error of 0.015) compared with 0.041 for our contemporaneous income measure.

${ }^{29} \mathrm{Blau}$ (1999) estimates slightly larger (though substantially less precise) effects of average family income when controlling for unobserved grandparent fixed effects (i.e. comparing children whose mothers are sisters).

${ }^{30}$ For SIV, it is less important to control for all $z_{i}$ regressors since we include the polynomial in lagged pre-tax income. We obtain very similar SIV estimates when we exclude these regressors (while continuing to include the 
Table 3 reports baseline SIV and PSIV estimates for our combined math-reading achievement measure, as well as each of the individual PIAT subject test measures. Both the SIV and PSIV estimates suggest that a $\$ 10,000$ increase in family income raises math-reading achievement by nearly 0.6 standard deviations, a modest effect, but larger than the comparable OLS estimates. The estimated effects of income are about half as large for reading recognition, while estimated effects of income on reading comprehension and math are similar to or slightly larger than the effects on our combined math-reading measure. Our SIV and PSIV estimates are remarkably similar despite using different sources of underlying variation - PSIV only uses variation in the instrument based on differences in observable family characteristics (e.g. maternal race, education, ability, and age) while SIV also exploits variation in unobserved determinants of family income. (The correlation between our instruments is only 0.60.) This table also reports the coefficient on our instrument in the first stage regression of changes in total family income on changes in predicted EITC receipt. All of the specifications predict that total income increases roughly one-for-one (or slightly more) with predicted EITC payments.

The primary assumption in our analysis is that the relationship between child achievement and either lagged pre-tax income (SIV) or exogenous family $z_{i}$ characteristics (PSIV) must be stable over time if the EITC schedule is not changing. Identification relies on linking changes in these relationships with changes in the EITC schedule over time. Of particular concern are systematic economic or policy changes that would improve the test scores of children from lower-income families at the same time the EITC expanded (most notably from 1993 to 1995). In this case, our SIV and PSIV estimators would mistakenly attribute the achievement gains of disadvantaged children to the increased income their families received from expansions of the EITC. We explore specifications in Table 4 that take into account national time trends and changes in state-level school accountability and welfare policies. To conserve space, we only report estimates for our combined math-reading achievement measure.

As seen in the first column of Table 4, estimates which account for a linear time trend are slightly larger than those of Table 3 (a quadratic yields very similar estimates). It is important to remember that we are modelling changes in test scores, so these estimates allow for a linear rise or fall in achievement growth from 1988-2000. The SIV estimates also allow for a time trend in the control function (i.e. the interaction between year and the sixth order polynomial in pre-tax income), while the PSIV estimates include the interaction of year with all other regressors. The functions that interact all included regressors with the polynomial in income. 
inclusion of these interactions addresses the concern that the relationship between child outcomes and either pre-tax income or family characteristics is changing over time.

The next two columns in Table 4 address changes in state policies that might directly affect the relationship between child outcomes and family income or characteristics: school accountability policies and welfare regulations. A few states began to introduce student testing/accountability measures and welfare reforms in the early 1990s, which some studies have linked to improvements in state test scores (e.g. Hanushek and Raymond (2005) and Miller and Zhang (2008)). ${ }^{31}$ To account for these reforms, we start by adding an annual indicator for whether the child's state has a 'consequential' accountability policy (i.e. required testing with consequences for school performance) to our baseline specification of Table $3 .^{32}$ These results, reported in the second column of Table 4 , are very similar to the baseline estimates. The next column examines whether accounting for welfare reforms taking place in the 1990s (associated with statewide AFDC waivers and TANF) affects our results. We include in our baseline specification an annual indicator equal to one if a state has any of the following: (a) time limits on welfare receipt, (b) sanctions for violating work requirements, or (c) school requirements for dependent children. As Table 4 shows, this has little affect on our estimates. Finally, the last column of Table 4 simultaneously accounts for national time trends, state-level school accountability, and state-welfare reforms. Again, the results are only slightly larger than our baseline estimates and very similar to those accounting for time trends alone. In summary, we find no evidence that time-varying policies or economic changes affect the estimated impacts of family income on child achievement.

In Table 5, we return to dynamic models of child achievement that allow for lasting effects of family income on children. We report estimates for the combined math-reading achievement measure analogous to those of Table 2. Due to to the limited number of major changes in the EITC schedule covered by our data, however, we are unable to separately estimate all of the effects of past income as we did with OLS. By necessity, the estimates of equation (2) in Panel A restrict some of the effects of past income to be the same. Column (i) of Panel A reproduces the baseline results from Table 3 for the sample used in this table. ${ }^{33}$ Column (ii) allows for the possibility that income affects test scores up to one year later, restricting the effects of income on both current

\footnotetext{
${ }^{31}$ Most states did not introduce school accountability policies or welfare reforms prior to 1996 . A number of states received Aid to Families with Dependent Children (AFDC) waivers in the early 1990s; however, most states introduced welfare reforms with the introduction of the Temporary Assistance for Needy Families (TANF) program in 1996. See Appendix C for a detailed description of our school accountability and welfare policy measures.

${ }^{32}$ These specifications also include an interaction of the accountability measure with the polynomial in pre-tax income (SIV) or all of the other regressors (PSIV). We do the same for welfare policy indicators below.

${ }^{33}$ For ease of comparison across specifications in the table, the samples are restricted to those with available income data for all ages $a$ back to $a-4$ as required by columns (iii) and (iv) in Panel A.
} 
and the following year's test score to be the same. Column (iii) allows the effect of income to last for two years, assuming it is constant over those years. Put another way, specifications (ii) and (iii) assume a constant effect of income on test scores for one or two years, with the effect falling to zero thereafter. As columns (i) to (iii) show, the estimated effect of income declines quickly when we assume that it lasts longer and longer. This is the type of pattern we would expect if income had a large contemporaneous effect on test scores but a negligible lasting effect. Column (iv) suggests that this is indeed the case. In this specification, we allow for a contemporaneous effect, $\delta_{0}$, and a separate effect that lasts for the next two years, $\delta_{1}=\delta_{2}$. For both SIV and PSIV, the contemporaneous effect is large and similar to the baseline results reproduced in column (i). In contrast, the estimated effect of income on achievement the following two years is negligible for SIV and negative for PSIV. It is difficult to interpret the latter.

Panel B of Table 5 reports estimates of equation (5), which allows for permanent effects of income on children. The estimates in column (i) reveal no permanent effect when we restrict the long-run effects of income to be the same as the contemporaneous effects. Column (ii) allows for the contemporaneous effect of income to differ from its long-run effect ( $\omega$ reflects this difference). SIV estimates a negligible long-run effect with a sizeable contemporaneous effect of income that is very similar to our baseline estimate. PSIV estimates a modest long-run effect and a very large contemporaneous effect of income; however, these PSIV estimates are very imprecise.

Despite the difficulty of estimating rich dynamic models of family income and child achievement, we draw two main conclusions from Table 5. First, we find little evidence that income has longrun effects on math and reading achievement test scores. Second, income appears to have modest contemporaneous effects on child achievement. Moreover, allowing for long-run effects of income does not substantially alter estimates of income's contemporaneous effect. So, while one would certainly like to more fully determine the dynamic effects of family income on achievement, the simple 'contemporaneous effects' model appears to provide good estimates of the short-run effects of income. We focus on this simple baseline model in what follows.

Table 6 reports separate estimates of the 'contemporaneous effects' model for different population subgroups. The estimates suggest that achievement for minorities (blacks or hispanics) responds more to additional income than does achievement for whites. Achievement for children with low educated mothers increases more with income than does the achievement of children with more educated mothers. Similarly, income raises test scores more among children in unmarried households relative to married households; however, the estimates for unmarried households are 
very imprecise (largely due to a poor first stage). Finally, the last set of estimates are based on stratifying the sample by predicted pre-tax family income. ${ }^{34}$ The PSIV estimates suggest stronger effects of income on children from families with low predicted income; however, the SIV estimates suggest the opposite. For the most part, these estimates suggest that the effects of family income are greater for more disadvantaged children; however, differences across groups are not generally statistically significant (the only significant difference is for PSIV estimates comparing low versus highly educated mothers).

A number of recent studies (e.g. Duncan and Brooks-Gunn 1997, Duncan, et al. 1998, Levy and Duncan 1999) suggest that income at early ages may have greater effects on development than income received at later ages. In Table 7, we allow for differential effects of contemporaneous income on achievement at ages 5-10 and ages 11-15. In these specifications, we include an indicator equal to one if the child is age 10 or less (zero otherwise) and interact this indicator with current family income. ${ }^{35}$ These estimates suggest that income has a larger effect on combined math-reading achievement for younger children; however, the difference is only statistically significant for SIV, and not PSIV. We also report estimates for each of the PIAT subtests separately. Unfortunately, PSIV estimates of the differential effect of income at young ages are very imprecise (the PSIV standard errors are roughly $50 \%$ larger compared to their SIV counterparts). Focusing on the more precisely estimated SIV estimates, we generally find stronger effects of income on both math and reading achievement among younger children. The differential effect by age is most pronounced for reading recognition, which shows negligible effects of family income for older children but sizeable effects on younger children. Unfortunately, we are unable to examine the contemporaneous effects of income at very early ages, which is when many researchers find the largest effects. This is because children do not take the PIAT tests in the NLSY until age five. ${ }^{36}$

In Table 8, we present several additional specifications for the 'contemporaneous effects' model (combined math-reading measure) to explore the robustness of our baseline results. We begin by including additional control variables for a mother's family background and spousal characteristics in the differenced child outcome equation. The additional variables are listed in panels $\mathrm{C}$ and $\mathrm{D}$ of Appendix Table B1. These additional controls do little to change the PSIV estimate, but increase both the estimate and standard error for SIV. We next explore a more general control function for

\footnotetext{
${ }^{34}$ We use the same $z_{i}$ family characteristics to predict pre-tax family income here as we do for PSIV. To split our sample by predicted income, we use the median predicted pre-tax income in our sample, $\$ 16,558$.

${ }^{35}$ To instrument for the interaction term, we interact our SIV or PSIV instrument with the age $\leq 10$ indicator.

${ }^{36}$ In principle, it is possible to estimate whether early income (including income received prior to age 5) affects PIAT scores at younger ages (e.g. ages 5-7); however, this proved difficult in practice due to small sample sizes and the difficulties in separating out the short-term and longer-term effects of income as discussed earlier.
} 
SIV. In this specification, we interact all of the baseline control variables used in Table 3 with a sixth order polynomial in lagged income (i.e. interactions with the covariates listed in panels A and B of Appendix Table B1). These interactions address the concern that the relationship between child outcomes and lagged income differs based on the baseline controls. This more general control function does not appreciably change the estimate. Panel C incorporates state EITC payments as an additional source of exogenous variation used to construct our instruments. Taking advantage of this extra state-level variation changes the estimates only slightly, since few states had EITC provisions in their tax laws during our sample period (5 states by 1996 and 10 states by 1999). ${ }^{37}$ To help alleviate concerns about less than full take-up rates for the EITC, we estimate the baseline specification for the sample of children living in the 25 states with the highest estimated EITC filing rates in 1996 (84.6\% or higher) according to the Internal Revenue Service (2002). As reported in Panel D, the estimated effects of family income are similar to the baseline results for the full sample.

Table 6 suggests the effects of income may be stronger for more disadvantaged children. Under this assumption, some researchers have preferred to measure income in logs rather than levels. For comparison and as a check on the robustness of our findings, Panel E of Table 8 uses log total family income as the right-hand side variable rather than income measured in levels. Both SIV and PSIV reveal significant effects of log family income, which imply that a $10 \%$ increase in family income raises achievement by 8-9 percent of a standard deviation. For families with income of $\$ 12,000$, an extra $\$ 1,000$ would raise scores by 0.066 of a standard deviation (SIV) or 0.070 (PSIV), magnitudes that are similar to our baseline estimates when income is measured in levels. ${ }^{38}$

It is natural to question whether the large changes in the EITC generated important labor supply responses among mothers which may have affected children separately from the direct effects of income we aim to measure. ${ }^{39}$ If so, our strategy will attribute these additional effects to income unless we also control for parental labor supply. Most empirical studies find very small negative effects of the EITC expansions on hours worked by women who were already working. There

\footnotetext{
${ }^{37}$ State EITCs are expressed as a percentage of the federal EITC, usually with the same eligibility requirements. In this specification, we also include state fixed effects. The addition of state fixed effects has little impact on the coefficient of interest, regardless of whether we use the state EITCs to construct our instruments.

${ }^{38}$ As an instrument for $\Delta \ln \left(I_{i a}\right)$ in this specification, we use $\ln \left(P_{i, a-1}+\chi_{a}^{s_{i, a-1}}\left(P_{i, a-1}\right)\right)-\ln \left(P_{i, a-1}-\chi_{a-1}^{s_{i, a-1}}\left(P_{i, a-1}\right)\right)$ for SIV and a similar expression for PSIV. The sample size for SIV is smaller in the log specification, since observations are dropped whenever $P_{i, a-1}=0$.

${ }^{39}$ In principle, an EITC expansion may affect children in three ways. First, holding earnings constant, it increases family income. Second, it may affect earnings through family labor supply responses. Both of these affect children through available family resources. Finally, labor supply responses may directly affect children through parental time spent with children. If labor supply responses to EITC schedule changes are small, the second and third effects will be negligible, and we identify only the first effect. More generally, in controlling for labor supply, we identify the sum of the first two effects (i.e. the effect of the total change in income).
} 
appears to be a positive effect on labor market participation among single mothers, but small negative effects on married mothers with working husbands (see Hotz and Scholz 2003 and Eissa and Hoynes 2005). In Panel F of Table 8, we add changes in maternal labor force participation and hours worked to our baseline specifications as additional controls. An increase in the number of hours a mother works has small negative estimated effects on children, whereas participation changes have statistically insignificant effects. Most importantly, accounting for changes in mother's labor market participation and hours of work does not affect our main conclusion about the importance of family income. ${ }^{40}$

\subsection{Interpreting SIV and PSIV Estimates}

Our SIV and PSIV results indicate modest but encouraging effects of family income on children's scholastic achievement. Our baseline estimates imply that a $\$ 1,000$ increase in income raises combined math and reading test scores by $6 \%$ of a standard deviation. Although modest in an absolute sense, our estimates are large relative to most of the literature and relative to the OLS and differenced estimates reported in Table 2. Duncan, Morris, and Rodrigues (2007) also report IV estimates of the effect of family income on child achievement that are much larger than their OLS estimates. Their IV strategy exploits randomly assigned variation in family income supplements from ten different income support and welfare experiments to identify the causal effect of income. Their IV estimates are nearly identical to our baseline SIV and PSIV estimates. Like our approach, their strategy uses exogenous variation in income and focuses on relatively disadvantaged families.

We speculate that a variety of factors may be responsible for our larger SIV and PSIV estimates relative to traditional OLS and fixed effects or differenced estimates. A first possibility is that measurement error produces attenuation bias for standard methods. Fixed effects and differenced estimators are particularly affected by this problem, since changes in income are noisier than income measured in levels. Our IV strategies are largely unaffected by measurement error in income. However, measurement error alone is unlikely to explain most of the gap between our instrumental variable estimates and more traditional estimates. As reported in Section 5.1, the estimated effect of average income (which should have less measurement error) is twice as large as the estimated

\footnotetext{
${ }^{40}$ The endogeneity of which mothers work and how much they choose to work is an obvious concern. We attempted to treat participation as endogenous by using changing parameters of the EITC schedules (e.g. maximum credit amounts, phase-in and phase-out rates) over time as additional instrumental variables for maternal labor market participation (an approach similar in spirit to Blundell, et. al 1998, and Eissa and Hoynes 2006). This approach yields statistically significant estimates for family income that are very similar to our baseline estimates; however, it produces imprecise estimates for maternal labor supply. Unfortunately, the first stage for maternal labor supply indicates the instruments are weak in our sample, so we do not place much weight on these findings.
} 
effect of contemporaneous income in OLS specifications (.08 versus .04), but still much smaller than our IV estimates.

A second potential explanation is that income matters more for disadvantaged families and that our SIV and PSIV estimates capture the effects of income for disadvantaged families who are affected by the EITC expansions. Table 6 offers some support for this explanation. To further explore this issue, we split the sample into low, middle, and high average total family income groups and used OLS to estimate separate effects of income for each group. ${ }^{41}$ The effect of a $\$ 10,000$ increase in average income is 0.30 (standard error of 0.12 ) for the bottom quartile, 0.10 (0.04) for the middle two quartiles combined, and 0.06 (0.03) for the highest quartile. The effect for the lowest income group is much larger than the effects for higher income groups and much closer to our SIV and PSIV estimates.

A third explanation recognizes that each EITC expansion effectively raised the annual incomes of eligible families for many years in the future. For example, we estimate that for the median EITC recipient, the 1993-95 EITC expansion raised total credit amounts over the years 1995-99 by nearly five times the amount it raised credit amounts in 1995 alone. ${ }^{42}$ If families are forwardlooking and base their investment decisions on current and expected future income, we would expect them to respond more to a lasting change in income than to a one-year change. A lasting increase in income is also likely to alleviate family stress and improve family dynamics more than a comparable temporary increase. In this case, our SIV and PSIV estimators identify the effect of increasing annual income by $\$ 10,000$ for many years into the future and not just a single year. On the other hand, OLS and difference estimators identify the effect of a much more short-lived increase in income, since most of the underlying variation in income over time is transitory (or measurement error). ${ }^{43}$ Thus, it is not surprising that our SIV and PSIV estimators exceed our OLS and difference estimators.

A final possible explanation for the larger effects of SIV and PSIV estimators may have to do

\footnotetext{
${ }^{41}$ Given the NLSY oversampling of minorities and poor whites, our data contains a large number of low and moderate income families. The lowest quartile corresponds to families earning less than $\$ 10,443$ on average, the middle two quartiles between $\$ 10,443$ and $\$ 25,356$, and the fourth quartile greater than $\$ 25,356$. We use average income rather than current income to minimize problems with measurement error and to capture more permanent differences in income.

${ }^{42}$ To empirically investigate the persistence of EITC gains for families, we divide the cumulative three-year credit increase (for 1995, 1997, and 1999) by the one-year credit increase for 1995 resulting from the large EITC expansion that took place between 1993 and 1995. Specifically, we calculate $\frac{\left[\chi_{95}\left(P_{95}\right)+\chi_{95}\left(P_{97}\right)+\chi_{95}\left(P_{99}\right)\right]-\left[\chi_{93}\left(P_{95}\right)+\chi_{93}\left(P_{97}\right)+\chi_{93}\left(P_{99}\right)\right]}{\chi_{95}\left(P_{95}\right)-\chi_{93}\left(P_{95}\right)}$, where $\chi_{s}\left(P_{t}\right)$ reflects the simulated EITC credit based on the schedule from year $s$ and pre-tax income reported for year $t$. The median of this ratio (for those who received any EITC in 1995) is 2.85, while the 25th and 75th percentiles of this ratio are 2.28 and 3.43, respectively. Extrapolating based on the median ratio implies that a $\$ 1$ increase in current EITC income translates into a $\$ 4.75$ increase in EITC income over the next five years.

${ }^{43}$ See Dahl and Lochner (2005) for a more formal discussion of these issues.
} 
with the nature of EITC income relative to other income sources. Three features of the EITC are somewhat special. First, the EITC is typically paid out in lump sum fashion after families file their taxes, and families may spend these lump-sum transfers differently than they spend more traditional income flows (Barrow and McGranahan (2000) and Goodman-Bacon and McGranahan (2008)). Second, since EITC payments explicitly depend on having children in the household, families may feel some obligation to spend it on their children. Third, EITC payments come in the mail with tax returns or are direct deposited into family accounts. As such, mothers may be more likely to gain control of EITC payments than fathers (compared to other sources of income). A number of recent studies empirically find that household expenditures on children increase with the share of family income going to mothers (e.g. Lundberg, Pollak, and Wales 1997, Attanasio and Lechene 2002, and Ward-Batts 2008).

\section{Conclusion}

Understanding the consequences of growing up poor for a child's well-being is an important research question, but one that is difficult to answer due to the potential endogeneity of family income. The question is particularly interesting to policymakers, since part of the explicit rationale for income support programs (such as the EITC) is to improve the lot of children. Past estimates of the effect of family income on child development have often been plagued by omitted variable bias. That is, children growing up in poor families are likely to have home environments or face other challenges which would continue to affect development even if family income rose substantially.

In this paper, we use two related instrumental variables strategies (SIV and PSIV) to estimate the causal effect of income on children's math and reading achievement. Using a panel of 4,720 children matched to their mothers allows us to address problems associated with both unobserved heterogeneity and endogenous transitory income shocks. Our SIV and PSIV strategies exploit the large non-linear changes in the EITC over the last two decades as an exogenous source of variation in family income levels. The largest of these EITC changes doubled benefit amounts for some families, accounting for as much as $\$ 2,100$ in extra income. Over the time period in our sample, the EITC expansions raised average family income by $10 \%$ for EITC eligible families with two or more children.

We find that extra family income has a modest, but encouraging, causal effect for children growing up in poor families. Our SIV and PSIV results indicate that current income has significant effects on a child's math and reading test scores. The baseline estimates imply that a $\$ 1,000$ increase 
in income raises contemporaneous math and reading test scores by $6 \%$ of a standard deviation. Consistent with the recent literature on the relative importance of income received during early childhood, we find some evidence that family income has larger impacts on younger children (ages 5-10 vs. 11-15). The results are robust to a variety of alternative specifications, including regressions which account for time-varying state policies, more general control functions, and maternal labor market participation. However, we find little evidence that the effect of income lasts very long. In order to sustain an increase in test scores, our estimates imply that income supplements must be maintained year after year (as is the case after an EITC expansion). An interesting avenue for future research would be to explore why income (received at primary and middle-school ages) has modest contemporaneous effects but negligible long-run effects on achievement test scores.

\section{References}

[1] A. Attanasio and V. Lechene. Tests of Income Pooling in Household Decisions. Review of Economic Dynamics, 5:720-748, 2002.

[2] L. Barrow and L. McGranahan. The Effects of the Earned Income Credit on the Seasonality of Household Expenditures. National Tax Journal, 53(4):1211-1243, 2000.

[3] D. Blau. The Effect of Income on Child Development. Review of Economics and Statistics, 81(2):261-276, May 1999.

[4] R. Blundell, A. Duncan, and C. Meghir. Estimating Labor Supply Responses Using Tax Reforms. Econometrica, 66:827-61, 1998.

[5] P. Carniero and J. Heckman. The Evidence on Credit Constraints in Post-Secondary Schooling. Economic Journal, 112:705-34, 2002.

[6] Center on Budget and Policy Priorities. The 2005 Earned Income Tax Credit Outreach Kit. Washington, D.C., 2005.

[7] Child Trends and Center for Child Health Research. Early Child Development in Social Context. New York, 2004.

[8] J. Currie and J. Gruber. Saving Babies: The Efficacy and Cost of Recent Changes in the Medicaid Eligibility of Pregnant Women. Journal of Political Economy, 106(6):1263-96, 1996.

[9] G. Dahl and L Lochner. The Impact of Family Income on Child Achievement. NBER Working Paper No. 11279, 2005.

[10] G. Duncan and J. Brooks-Gunn. Consequences of Growing Up Poor. Russell Sage Foundation, New York, 1997. 
[11] G. Duncan, P. Morris, and C. Rodrigues. Does Money Really Matter? Estimating Impacts of Family Income on Young Children's Achievement with Data from Random-Assignment Experiments. Working Paper, 2007.

[12] G. Duncan, W. Yeung, J. Brooks-Gunn, and J. Smith. How Much Does Childhood Poverty Affect the Life Chances of Children? American Sociological Review, 63:406-423, June 1998.

[13] N. Eissa and H. Hoynes. Behavioral Responses to Taxes: Lessons from the EITC and Labor Supply. Tax Policy and the Economy, 20:74-110, 2005.

[14] N. Eissa and H. Hoynes. The Hours of Work Response of Married Couples: Taxes and the Earned Income Tax Credit. In J. Agell and P.B. Sorensen, editors, Tax Policy and Labor Market Performance, pages 187-228. MIT Press, 2006.

[15] D. Feenberg and E. Coutts. An Introduction to the TAXSIM Model. Journal of Policy Analysis and Management, 12(1):189-94, 1993.

[16] M. Feldstein. Behavioral Responses to Tax Rates: Evidence from the Tax Reform Act of 1986. American Economic Review, 85(2):170-74, 1995.

[17] A. Goodman-Bacon and L. McGranahan. How do EITC Recipients Spend their Refunds? Economic Perspectives, 2Q:17-32, 2008.

[18] J. Gruber and E. Saez. The Elasticity of Taxable Income: Evidence and Implications. Journal of Public Economics, 84(1):1-32, 2002.

[19] E. Hanushek and M. Raymond. Does School Accountability Lead to Improved Student Performance? Journal of Policy Analysis and Management, 24(2):297-327, 2005.

[20] R. Haveman and B. Wolfe. The Determinants of Children's Attainments: A Review of Methods and Findings. Journal of Economic Literature, 33(4):1829-1878, Dec. 1995.

[21] V. J. Hotz and J. K. Scholz. The Earned Income Tax Credit. In R. Moffit, editor, Means-Tested Transfer Programs in the U.S. The University of Chicago Press, Chicago, 2003.

[22] Internal Revenue Service. Participation in the Earned Income Tax Credit Program for Tax Year 1996. Washington, D.C., 2002.

[23] B. Jacob, L. Lefgren, and D. Sims. The Persistence of Teacher-Induced Learning Gains. NBER Working Paper No. 14065, 2008.

[24] D. Levy and G. Duncan. Using Sibling Samples to Assess the Effect of Childhood Family Income on Completed Schooling. Working Paper, 1999.

[25] J. R. Lockwood, D. McCaffrey, L. Mariano, and C. Setodji. Bayesian Methods for Scalable Multivariate Value-Added Assessment. Journal of Educational and Behavioral Satistics, 32(2):125-50, June 2007. 
[26] S. J. Lundberg, R. A. Pollak, and T. J. Wales. Do Husbands and Wives Pool Their Resources? Evidence from the United Kingdom Child Benefit. The Jounal of Human Resources, 32(3):463480, 1997.

[27] S. Mayer. What Money Can't Buy: Family Income and Children's Life Chances. Harvard University Press, Cambridge, 1997.

[28] V. McLoyd. The Impact of Economic Hardship on Black Families and Children: Psychological Distress, Parenting and Socioemotional Development. Child Development, 61:311-46, 1990.

[29] A. Miller and L. Zhang. The Effects of Welfare Reform on the Academic Performance of Children in Low-Income Households. Working Paper, 2008.

[30] R. Moffitt and M. Wilhelm. Taxation and Labor Supply Decisions of the Affluent. In J. Slemrod, editor, Does Atlas Shrug? Economic Consequences of Taxing the Rich, chapter 7, pages 193-234. Russell Sage Foundation, New York, 2000.

[31] F. Parker, A. Boak, K. Griffin, C. Ripple, and L. Peay. Parent-Child Relationship, Home Learning Environment, and School Readiness. School Psychology Review, 28(3):413-25, 1999.

[32] J. Rothstein. Teacher Quality in Educational Production: Tracking, Decay, and Student Achievement. Working Paper, 2008.

[33] J. K. Scholz. The Earned Income Tax Credit: Participation, Compliance, and Anti-Poverty Effectiveness. National Tax Journal, 47(1):59-81, 1994.

[34] P. Todd and K. Wolpin. On the Specification and Estimation of the Production Function for Cognitive Achievement. Economic Journal, 113(485):3-33, 2003.

[35] P. Todd and K. Wolpin. The Production of cognitive Achievement in Children: Home, School, and Racial Test Score Gaps. Jounal of Human Capital, 1(1):91-136, 2007.

[36] U.S. Census Bureau, Current Population Reports, Series P60. Poverty in the United States: 2003. U.S. Government Printing Office, Washington, DC, 2004.

[37] J. Ward-Batts. Out of the Wallet and into the Purse. Using Micro Data to Test Income Pooling. The Jounal of Human Resources, 43(2):325-351, 2008. 


\section{Appendix A: Methodological Issues}

\section{Details on EITC, Tax, and Net Total Income Measures}

We create three family income categories based on the many income components in the NLSY: earned income, unearned income, and non-taxable income. Earned income includes income from wages and salary. Unearned income includes reported income from a business or farm, unemployment compensation, and a residual catch-all question referring to interest income, social security payments, net rental income, and income from other regular sources. Non-taxable income includes income from veteran benefits, worker compensation or disability payments, welfare payments (including food stamps, Supplementary Security Income, or other public assistance), educational scholarships or grants, and child support. All of these measures include income received by the mother as well as her spouse. (Income from unmarried partners is not included.)

To calculate actual EITC and tax amounts, we use both earned and unearned income, running them through TAXSIM for the appropriate year. ${ }^{44}$ These are added (EITC) to and subtracted (taxes) from pre-tax/EITC income to create our measure of total net family income, $I_{i a}$.

To calculate predicted EITC amounts for use in our instruments, we only input earned income (or predicted earned income) into TAXSIM. We do this, because unearned income amounts are generally quite low (and noisy) for persons otherwise qualifying for the EITC, and including unearned income would require the inclusion of a more complicated control function in SIV that depended on both earned and unearned income. The analysis is greatly simplified by leaving unearned income out, with little sacrificed in terms of identifying power.

\section{SIV Estimation of the Contemporaneous Effects Model}

To understand the implicit assumptions underlying the SIV strategy, begin by assuming that $\alpha=$ $\beta=0$ in equation (3). In this case, SIV will provide consistent estimates if

$$
E_{a}\left[\Delta \varepsilon_{i a} \mid P_{i, a-1}, \Delta \chi_{a}^{S I V}\right]=\Phi\left(P_{i, a-1}\right) .
$$

The $a$ subscript on the expectation on the left reflects that it is taken with respect to the age $a$ conditional distribution of $\Delta \varepsilon_{i a}$. The key assumptions underlying this approach are (i) the control function $\Phi(\cdot)$ is flexible enough to capture the true expected relationship between child development shocks and pre-tax income, and (ii) the stability of that relationship over time.

First, notice that $E_{a}\left[\Delta \varepsilon_{i a} \mid P_{i, a-1}, \Delta \chi_{a}^{S I V}\left(P_{i, a-1}\right)\right]=E_{a}\left[\Delta \varepsilon_{i a} \mid P_{i, a-1}\right]$ if factors affecting the EITC schedule, $s_{i a}$, do not affect the relationship between shocks to child outcomes and pre-tax income. If everyone was on the same schedule, this would be trivially satisfied since $\Delta \chi_{a}^{S I V}$ would only be a function of pre-tax income. Endogeneity problems can be traced to the relationship between $\Delta \varepsilon_{i a}$ and $\left(P_{i, a-1}, P_{i a}\right)$. Stability of this relationship over time (i.e. $E_{a}\left(\Delta \varepsilon_{i a} \mid P_{i, a-1}, P_{i a}\right)=$

\footnotetext{
${ }^{44}$ We put all unearned income through TAXSIM as 'unemployment income' since the program treats it as fully taxable income during our sample period, but it appropriately does not treat it as earned income in computing the EITC. While in later years persons with 'excessive' interest and dividend income (above $\$ 2,200-2,500$ depending on the year) should be disqualified from the EITC, we are unable to separate this source of income from social security payments, rental income or other regular sources of income. By including this income with other unearned income and putting it through TAXSIM as 'unemployment income', we effectively ignore this feature of the EITC rules.
} 
$E\left(\Delta \varepsilon_{i a} \mid P_{i, a-1}, P_{i a}\right)$ so the expectation no longer depends on age, $\left.a\right)$ and stationarity of the income evolution process (i.e. $g\left(P_{i, a-1}, P_{i a}\right)=g\left(P_{i, a^{\prime}-1}, P_{i a^{\prime}}\right)$ for all $\left.a, a^{\prime}\right)$ further implies that $E_{a}\left[\Delta \varepsilon_{i a} \mid P_{i, a-1}\right]=$ $E\left[\Delta \varepsilon_{i a} \mid P_{i, a-1}\right]=\Phi\left(P_{i, a-1}\right)$ for a sufficiently flexible function $\Phi(\cdot)$.

More generally, when $\alpha$ and $\beta$ are not zero, one can incorporate $x_{i}$ and $\Delta w_{i a}$ into the control function. The estimates would then be consistent if

$$
E_{a}\left[\Delta \varepsilon_{i a} \mid x_{i}, \Delta w_{i a}, P_{i, a-1}, \Delta \chi_{a}^{S I V}\right]=\Phi\left(x_{i}, \Delta w_{i a}, P_{i, a-1}\right) .
$$

Estimating such a general control function can be empirically difficult due to the curse of dimensionality. Most of our regressors are indicator variables. In practice, we explore control functions with high order polynomials in $P_{i, a-1}$ and interactions of those polynomials with all of our regressors. In general, the inclusion of interaction terms has negligible effects on estimates of our parameters of interest, and the more simple $\Phi\left(P_{i, a-1}\right)$ is sufficient.

\section{PSIV Estimation of the Contemporaneous Effects Model}

PSIV first projects pre-tax income, $P_{i, a-1}$, onto exogenous $z_{i}$ characteristics and then uses the simulated change in EITC payments as a function of predicted income as an instrument for actual income changes. Because the instrument $\Delta \chi_{a}^{P S I V}$ is a function only of $z_{i}$ (and the exogenous EITC schedule changes), if $E\left(\varepsilon_{i a} \mid z_{i}\right)=0$ for all time periods, then $E\left(\Delta \varepsilon_{i a} \mid \chi_{a}^{P S I V}\right)=0$ and the instrument is valid. Intuitively, this means different types of families (i.e. those with different values of $z_{i}$ ) cannot receive different shocks, on average. In our case, children from families with $z_{i}$ characteristics that make them likely to receive a large EITC increase cannot simultaneously experience relatively large positive or negative unobserved achievement shocks. Since $z_{i}$ is included (along with other regressors) in the child outcome equation, we allow for the possibility that $z_{i}$ characteristics affect child test score growth. The key assumption is that these exogenous characteristics have the same direct affect on achievement growth during all years of our sample.

\section{SIV and PSIV Estimation of Models with Short- and Long-Run Effects}

Estimating more general first-difference models with lagged changes in income or income in levels like those of equations (2) or (5) requires additional instruments for each new income term. We use instruments analogous to those described above. For example, when we estimate equation (2) using SIV, we use $\chi_{a-\ell}^{s_{i, a-1}}\left(P_{i, a-1}\right)-\chi_{a-\ell-1}^{s_{i, a-1}}\left(P_{i, a-1}\right)$ as an instrument for $\Delta I_{i, a-\ell \cdot} \cdot{ }^{45}$ Using PSIV to estimate this equation, we use $\chi_{a-\ell}^{s_{i, a-1}}\left(\hat{P}_{i, a-1}\right)-\chi_{a-\ell-1}^{s_{i, a-1}}\left(\hat{P}_{i, a-1}\right)$ as an instrument for $\Delta I_{i, a-\ell}$. In estimating equation (5), we use $\chi_{a}^{s_{i, a-1}}\left(P_{i, a-1}\right)$ or $\chi_{a}^{s_{i, a-1}}\left(\hat{P}_{i, a-1}\right)$ as instruments for $I_{i, a}$ when using SIV or PSIV, respectively. In the case of SIV, it is still necessary to include the control function $\Phi\left(P_{i, a-1}\right)$, and the assumptions discussed above must still be satisfied. In the case of PSIV, we also include high order polynomials in $\hat{P}_{i, a-1}$ in estimating equation (5) to ensure identification from

\footnotetext{
${ }^{45}$ Notice, all simulated EITC changes are based on the schedule and pre-EITC income level as of age $a-1$. This maintains tractability, since it does not require inclusion of other lagged values of pre-EITC income in the control function $\Phi\left(P_{i, a-1}\right)$. Using different levels of pre-EITC income to simulate EITC changes for different lags (e.g. using $\chi_{a-\ell}^{s_{i, a-1}}\left(P_{i, a-\ell-1}\right)-\chi_{a-\ell-1}^{s_{i, a-1}}\left(P_{i, a-\ell-1}\right)$ as an instrument for $\left.\Delta I_{i, a-\ell}\right)$ would require including all of those pre-EITC income levels in the control function.
} 
changes in the EITC schedule over time rather than changes in the relationship between $P_{i, a-1}$ and $z_{i}$.

\section{Estimating Equations using Two-Year Differences}

Our data only contain measures of child outcomes every other year; however, our model of child outcomes (equation (1)) is based on annual income. We assume (1) describes child outcomes; however, we estimate our models using two-period differences. If we define $\Delta_{2}$ to be the two-period difference operator (e.g. $\Delta_{2} y_{i a}=y_{i a}-y_{i, a-2}$ ), then our model implies:

$$
\Delta_{2} y_{i a}=x_{i}^{\prime} \alpha+\Delta_{2} w_{i a}^{\prime} \beta+\Delta_{2} I_{i a} \delta_{0}+\Delta_{2} I_{i, a-1} \delta_{1}+\ldots+\Delta_{2} I_{i, a-L} \delta_{L}+\Delta_{2} \varepsilon_{i a} .
$$

We estimate versions of this equation for $L=0,1,2,3$ with various restrictions on the $\delta$ parameters. While estimation of the 'contemporaneous effects' model (i.e. $L=0$ ) does not require income data for years in-between when child outcome measures are observed, estimation of all other models does. Our model with permanent effects on children (see equation (5)) is estimated as follows:

$$
\Delta_{2} y_{i a}=x_{i}^{\prime} \alpha+\Delta_{2} w_{i a}^{\prime} \beta+\Delta_{2} I_{i a} \omega+\left(I_{i a}+I_{i, a-1}\right) \delta_{1}+\Delta_{2} \varepsilon_{i a}
$$

\section{Appendix B: Description of NLSY Children Data}

\section{Child Characteristics}

Most child characteristics are taken directly from the Children of the NLSY survey responses in even numbered years from 1986 to 2000. PIAT math and reading tests were administered biannually to children ages five to fifteen. ${ }^{46}$ We create normalized measures of PIAT math and reading using the standardized scores. These scores are initially normed by the NLSY based on a random sample of children in 1968 to have a constant mean (100) and standard deviation (15) for each age. For interpretation purposes, we re-normalize math, reading recognition, and reading comprehension scores by subtracting the sample mean from the NLSY random sample and then dividing by the sample standard deviation. This produces individual test scores with a mean of zero and standard deviation of one for the random sample of respondents. To create a combined math-reading score, we average the normalized math and reading measures and then re-normalize to a mean of zero and standard deviation of one (based on the random sample).

\section{Parental Characteristics}

Most parental characteristics are taken directly from the NLSY. Additionally, we create an ageadjusted, normalized AFQT measure using the percentile scores based on the 1979 calculation. We

\footnotetext{
${ }^{46}$ Children in our sample completed the math and the reading recognition test $75 \%$ of the time. Many children ages 5-7 do not have valid scores for the reading recognition test, because their scores were out of range based on the national norming sample in 1968. Starting in 1994, the tests were given only to children who had not reached their 15 th birthday by the end of the calendar year. Around two percent of children took the PIAT tests after their 15 th birthday before this rule was put in place. We include these children in our analysis, but the results are very similar if they are excluded. See the NLSY79 User's Guide for details.
} 
first create a normalized value by subtracting off the mean from the random sample and dividing by the sample standard deviation. Then, we regress these normalized scores on age dummies and use the residuals from this regression as our adjusted AFQT measure. We also fill in missing values for education and marital status using observed values in surrounding years.

\section{Family Income}

We calculate total family income combining all available measures of income in the NLSY, deflating them using the annual CPI-U so that they are in year 2000 dollars. Because some of the income components are missing in one or more years, we use a detailed imputation procedure to maintain a large representative sample. (We note, however, that imputations play little role in estimation of our contemporaneous effects model; they are more important for models with lagged income.) We begin by describing the available measures of family income from a battery of questions that vary slightly over time; then, we discuss imputation of missing values. Appendix A discusses details regarding the aggregation of these measures into total family income and determining EITC and tax amounts.

We utilize reported income of the respondent (i.e., the child's mother) and her spouse from the following sources: (i) wages, salary and tips (including income from military service); (ii) business and farm income; (iii) unemployment income; (iv) income from savings, net rental income, and social security income; (v) educational benefits from grants or scholarships; (vi) veteran benefits, worker compensation, and disability payments; (vii) welfare/AFDC, food stamps, Supplemental Security Income or other public assistance; and (viii) child support.

For all survey years (1979-1994, 1996, 1998, 2000), we impute each of these income sources separately based on the full panel of responses for individuals. Our different imputations largely reflect the relative importance of each income measure in computing total family income. Sources (i)-(iii) are imputed separately for the mother and her spouse, while all other sources are combined for both and imputed as a single measure. For wage, salary, and military income (source i), we use an individual-specific regression of income on age and age-squared to impute missing income observations. Only observations when an individual is age 22 or older are used in the regression, and we only impute missing observations when at least 8 positive observations are available. To impute missing observations for sources (ii) and (iv), we use individual-specific regressions of income on age (only using observations when an individual is age 22 or older and requiring at least 6 positive values). To impute missing observations for all other sources, we use individual-specific means (for ages 22 or older when at least 4 positive values are available). For non-survey years 1995, 1997, and 1999, we impute each income source as the average of adjacent year reports. (More detailed notes on the imputation procedure are available from the authors upon request.) We also trim the sample to exclude the approximately $1 \%$ of observations where total family income from all sources before taxes is above $\$ 100,000$ (in year 2000 dollars). 


\section{Appendix C: State-level School Accountability and Welfare Reform Measures}

Our measures of accountability and welfare reform are taken from Appendix Table 2 of Miller and Zhang (2008). Their accountability measures are largely due to Hanushek and Raymond (2005), who distinguish between 'consequential' accountability, which attaches consequences to school performance, and 'report card' accountability, which simply provides public report cards for schools. Their data reports three states as introducing accountability in '1993 or earlier'. Based on checks of State Department of Education websites, we code the introduction of accountability in Wisconsin as 1991, North Carolina as 1993, and Connecticut as 1988. Other states that were early to introduce 'consequential' accountability include Texas (1994) and Kentucky (1995).

Miller and Zhang (2008) document the introduction of three types of welfare reforms that took place at the state level since the early 1990s: limits on the amount of time a person (over a spell or over one's lifetime) can remain on welfare; sanctions (including partial or full reduction in welfare benefits) on recipients not meeting work or schooling requirements; and schooling requirements for children (e.g. maintaining minimum grades or requiring attendance). The following states introduced at least one of these reforms prior to 1996: New Jersey (1992); Illinois, Iowa, and Utah (1993); Arkansas, Georgia, Michigan, South Dakota, and Vermont (1994); Arizona, Indiana, Massachusetts, Mississippi, and Missouri (1995). 
Figure 1a: Federal EITC Schedules for Families with Two or More Children (2000 Dollars)

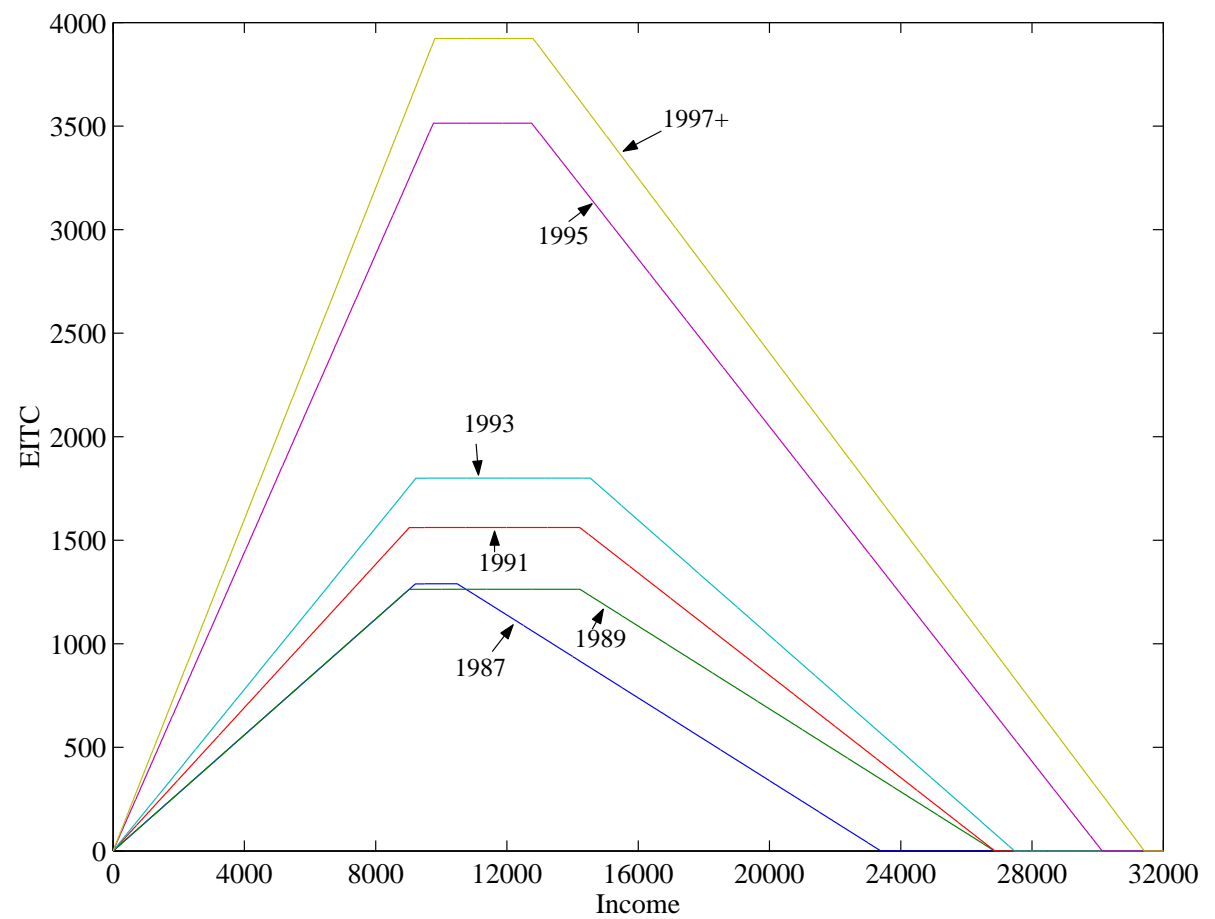

Figure 1b: Changes in Federal EITC Relative to 1987 for Families with Two or More Children (2000 Dollars)

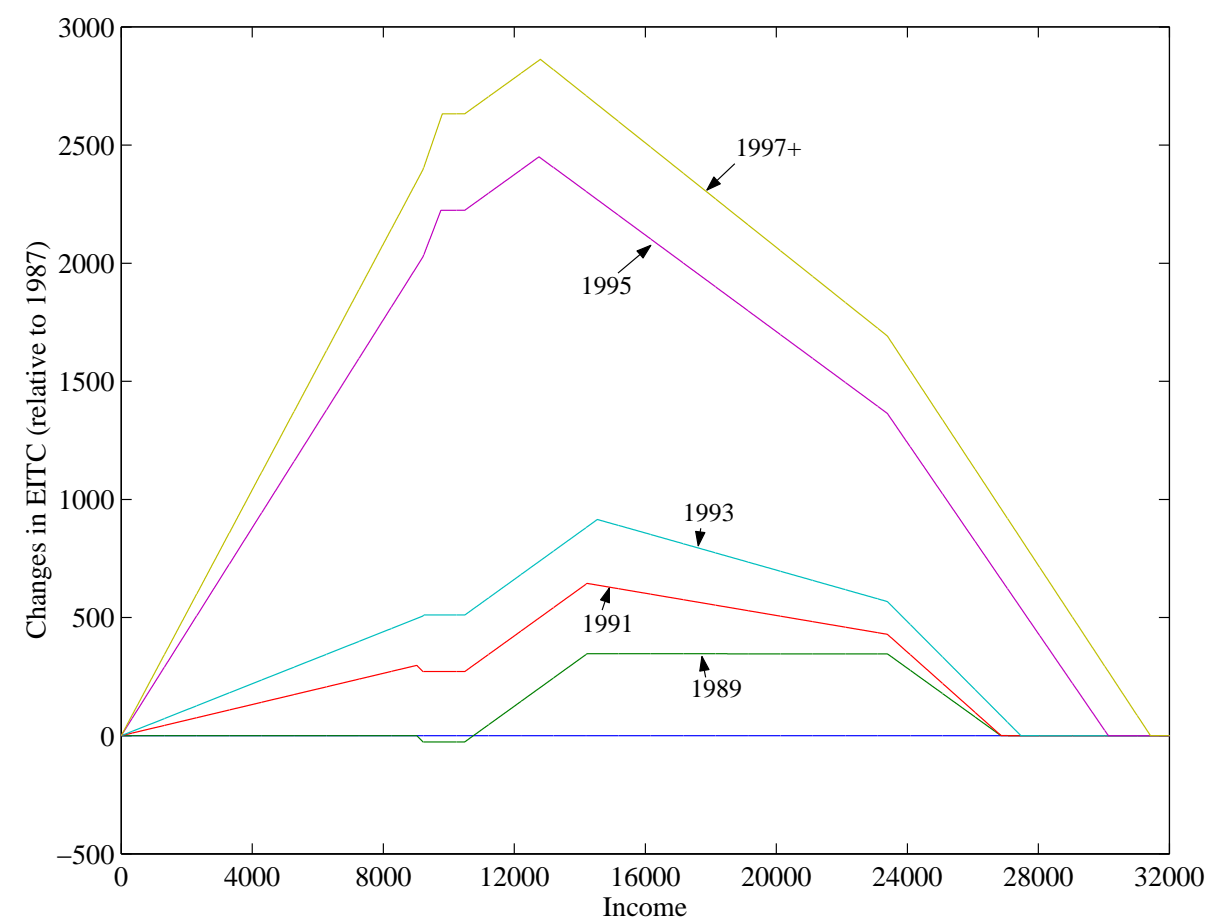


Table 1. Family Income, EITC Eligibility, and EITC Payments over Time (in Year 2000\$)

\begin{tabular}{|c|c|c|c|c|c|c|}
\hline \multirow[b]{2}{*}{$\begin{array}{l}\text { Year } \\
\text { (i) }\end{array}$} & \multirow[b]{2}{*}{$\begin{array}{l}\text { Number of } \\
\text { Children } \\
\text { (ii) }\end{array}$} & \multirow[b]{2}{*}{$\begin{array}{c}\text { Median Lagged } \\
\text { Family Income } \\
\text { (iii) }\end{array}$} & \multirow{2}{*}{$\begin{array}{c}\text { Fraction of } \\
\text { Children } \\
\text { in EITC } \\
\text { Eligible } \\
\text { Families } \\
\text { (iv) }\end{array}$} & \multirow{2}{*}{$\begin{array}{c}\text { Median EITC } \\
\text { Payment } \\
\text { (if Eligible) } \\
\text { (v) }\end{array}$} & \multicolumn{2}{|c|}{$\begin{array}{l}\text { EITC Payment as a } \\
\text { Fraction of Family } \\
\text { Income (if Eligible) }\end{array}$} \\
\hline & & & & & $\begin{array}{c}1 \text { Child } \\
\text { Families } \\
\text { (vi) }\end{array}$ & $\begin{array}{c}2+\text { Child } \\
\text { Families } \\
\text { (vii) }\end{array}$ \\
\hline 1988 & 1,375 & 16,207 & .48 & 662 & .07 & .05 \\
\hline 1990 & 1,375 & 15,994 & .60 & 771 & .06 & .06 \\
\hline 1992 & 1,949 & 16,104 & .59 & 999 & .09 & .07 \\
\hline 1994 & 1,865 & 16,472 & .60 & 1,130 & .10 & .08 \\
\hline 1996 & 1,865 & 19,377 & .69 & 2,044 & .12 & .13 \\
\hline 1998 & 1,536 & 20,624 & .70 & 2,253 & .13 & .15 \\
\hline 2000 & 1,245 & 22,615 & .68 & 2,163 & .12 & .15 \\
\hline All & 11,210 & 18,214 & .62 & 1,222 & .10 & .10 \\
\hline
\end{tabular}

Notes: Data are from the Children of the NLSY linked to their mothers in the main NLSY79. The unit of observation is a child. The sample is restricted to those used in our baseline SIV analysis in Table 3. Children must have valid math and reading PIAT scores, family background measures, and family income measures for the reported year. Children must also have at least two years of valid observations to be included. Year in column (i) refers to the NLSY survey year; income and EITC payment variables refer to the previous year's income. Family income includes tax payments and tax credits (including the EITC); the sources for family income include earned income, unearned income, and non-taxable income. 
Table 2: OLS Estimated Effects of Family Income on Math-Reading Achievement

\begin{tabular}{llll}
\hline \hline & (i) & (ii) & (iii) \\
\hline
\end{tabular}

A. Model: $y_{i a}=x_{i}^{\prime} \alpha_{a}+w_{i a}^{\prime} \beta+I_{i a} \delta_{0}+\ldots+I_{i, a-L} \delta_{L}+\mu_{i}+\varepsilon_{i a}$

1. Estimated in Levels

$\begin{array}{cccc}\delta_{0} & 0.041^{* *} & 0.037^{* *} & 0.037^{* *} \\ & (0.012) & (0.013) & (0.013) \\ \delta_{1} & & 0.005 & 0.004 \\ & & (0.013) & (0.014) \\ \delta_{2} & & & 0.002\end{array}$

$(0.010)$

2. Estimated in Differences

$\begin{array}{ccc}\delta_{0} & 0.012 & 0.012 \\ & (0.008) & (0.008) \\ \delta_{1} & & -0.001\end{array}$

$(0.010)$

B. Model: $y_{i a}=x_{i}^{\prime} \alpha_{a}+w_{i a}^{\prime} \beta+I_{i a} \delta_{0}+\left(I_{i, a-1}+\ldots+I_{i, 0}\right) \delta_{1}+\mu_{i}+\varepsilon_{i a}$

1. Estimated in Levels
$\delta_{0}=\delta_{1}$
$0.004^{* *}$
$\omega \equiv \delta_{0}-\delta_{1}$
$(0.002)$
$\delta_{1}$
0.008
$(0.017)$
0.004
$(0.002)$

2. Estimated in Differences
$\delta_{0}=\delta_{1}$
$0.005^{*}$
$\omega \equiv \delta_{0}-\delta_{1}$
(0.003)
$\delta_{1}$
0.010
$(0.009)$
0.004
(0.003)

Notes: Child achievement is a normalized average of math and reading scores. Income is measured in $\$ 10,000$ of year 2000 dollars. All regressions control for all variables listed in Appendix Table B1 plus a time trend. Difference estimators are based on two-period differences. Samples include children taking a math or reading PIAT test in the 1988 survey year or later. Sample size is 16,520 for all specifications in Panel A.1 and 10,401 for specifications in Panel A.2. Sample size is 10,125 in panel B.1 and 10,672 for Panel B.2. Standard errors are reported in parentheses and are clustered at the family level. **Significant at the $5 \%$ level, *significant at the $10 \%$ level. 
Table 3: Baseline Estimates of 'Contemporaneous Effects Model' using SIV and PSIV

\begin{tabular}{|c|c|c|c|c|}
\hline & $\begin{array}{l}\text { Combined Math } \\
\text { and Reading } \\
\text { (i) }\end{array}$ & $\begin{array}{c}\text { Reading } \\
\text { Recognition } \\
\text { (ii) } \\
\end{array}$ & $\begin{array}{c}\text { Reading } \\
\text { Comprehension } \\
\text { (iii) } \\
\end{array}$ & $\begin{array}{l}\text { Math } \\
\text { (iv) }\end{array}$ \\
\hline \multicolumn{5}{|l|}{ A. Simulated Instrumental Variables (SIV) } \\
\hline Effect of Current Income $\left(\delta_{0}\right)$ & $\begin{array}{c}0.603^{* *} \\
(0.216)\end{array}$ & $\begin{array}{c}0.357 \\
(0.224)\end{array}$ & $\begin{array}{c}0.717^{* *} \\
(0.276)\end{array}$ & $\begin{array}{c}0.600^{* *} \\
(0.281)\end{array}$ \\
\hline $1^{\text {st }}$ Stage Coeff. on SIV Instrument & $\begin{array}{c}1.291^{* *} \\
(0.284)\end{array}$ & $\begin{array}{c}1.140^{* *} \\
(0.272)\end{array}$ & $\begin{array}{c}1.338^{* *} \\
(0.286)\end{array}$ & $\begin{array}{c}1.155^{* *} \\
(0.266)\end{array}$ \\
\hline \multicolumn{5}{|c|}{ B. Projection-based Simulated Instrumental Variables (PSIV) } \\
\hline Effect of Current Income $\left(\delta_{0}\right)$ & $\begin{array}{c}0.595^{* *} \\
(0.180)\end{array}$ & $\begin{array}{l}0.268^{*} \\
(0.157)\end{array}$ & $\begin{array}{c}0.600^{* *} \\
(0.217)\end{array}$ & $\begin{array}{c}0.643^{* *} \\
(0.217)\end{array}$ \\
\hline $1^{\text {st }}$ Stage Coeff. on PSIV Instrument & $\begin{array}{c}1.200^{* *} \\
(0.246)\end{array}$ & $\begin{array}{c}1.201^{* *} \\
(0.246)\end{array}$ & $\begin{array}{c}1.226^{* *} \\
(0.245)\end{array}$ & $\begin{array}{c}1.202^{* *} \\
(0.244)\end{array}$ \\
\hline
\end{tabular}

Notes: Income is measured in $\$ 10,000$ of year 2000 dollars. All specifications control for 'variables used to predict earnings' and 'other baseline variables' listed in Appendix Table B1 and are estimated in two-year differences to account for unobserved child fixed effects. SIV also includes a sixth order polynomial in lagged pre-tax income. SIV sample sizes are 12,579 for reading recognition, 9,972 for reading comprehension, 12,728 for math, and 9,835 for the combined math and reading score (a normalized average of both reading and math scores). PSIV sample sizes are 12,575 for reading recognition, 9,970 for reading comprehension, 12,724 for math, and 9,833 for the combined math and reading score. Standard errors are reported in parentheses and are clustered at the family level. ${ }^{* *}$ Significant at the $5 \%$ level, * significant at the $10 \%$ level. 
Table 4: Estimates of 'Contemporaneous Effects Model' Accounting for Time Trend and Time-Varying State Policies (Math-Reading Achievement)

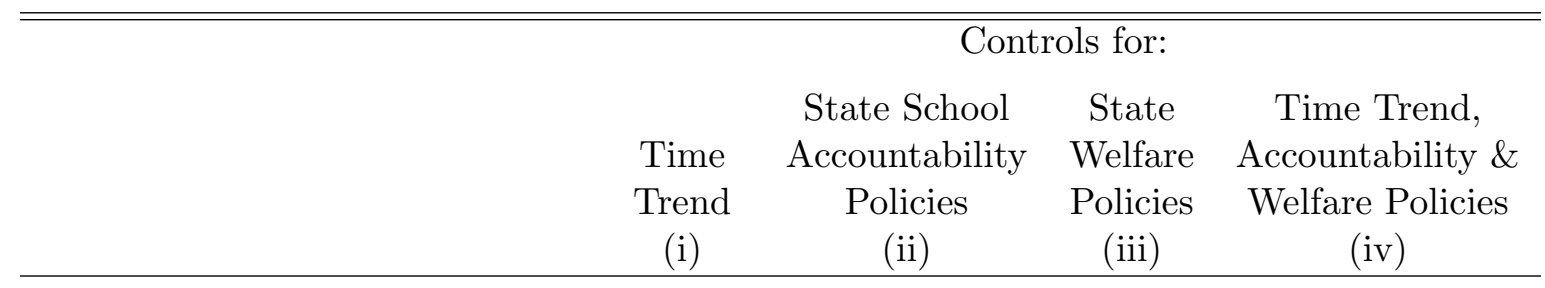

A. Simulated Instrumental Variables (SIV)

$\begin{array}{lcccc}\text { Effect of Current Income }\left(\delta_{0}\right) & \begin{array}{c}0.616^{* *} \\ (0.215)\end{array} & \begin{array}{c}0.612^{* *} \\ (0.214)\end{array} & \begin{array}{c}0.571^{* *} \\ (0.223)\end{array} & 0.608^{* *} \\ & (0.231)\end{array}$

$\begin{array}{lllll}\text { t-statistic from 1st Stage } & 4.59 & 4.61 & 4.31 & 4.27\end{array}$

B. Projection-based Simulated Instrumental Variables (PSIV)

$\begin{array}{ccccc}\text { Effect of Current Income }\left(\delta_{0}\right) & \begin{array}{c}0.699^{* *} \\ (0.204)\end{array} & \begin{array}{c}0.579^{* *} \\ (0.176)\end{array} & \begin{array}{c}0.579^{* *} \\ (0.168)\end{array} & 0.700^{* *} \\ & (0.211)\end{array}$

t-statistic from 1st Stage

$4.61 \quad 4.91$

5.27

4.53

Notes: Child achievement is a normalized average of math and reading scores. Income is measured in $\$ 10,000$ of year 2000 dollars. All specifications control for 'variables used to predict earnings' and 'other baseline variables' listed in Appendix Table B1. SIV specifications include interactions of reported controls (time trend, school accountability, and welfare policies) with a sixth order polynomial in lagged pre-tax income. PSIV specifications include interactions of reported controls with 'variables used to predict earnings' and 'other baseline variables' listed in Appendix Table B1. All specifications are estimated in two-year differences to account for unobserved child fixed effects. t-statistics are for SIV or PSIV instruments in the first-stage equation. Sample size is 9,835 for all SIV specifications and 9,833 for all PSIV specifications. Standard errors are reported in parentheses and are clustered at the family level. **Significant at the $5 \%$ level, * significant at the $10 \%$ level. 
Table 5: Estimates of Achievement Models with Long-Run Income Effects

(ii)

(iii)

A. Achievement Model: $y_{i a}=x_{i}^{\prime} \alpha_{a}+w_{i a}^{\prime} \beta+I_{i a} \delta_{0}+\ldots+I_{i, a-L} \delta_{L}+\mu_{i}+\varepsilon_{i a}$

1. Simulated IV
$\delta_{0}$
$0.557^{* *}$
$0.573^{* *}$
$(0.220)$
$\delta_{0}=\delta_{1}$
$0.232^{*}$
$(0.122)$
$\delta_{0}=\delta_{1}=\delta_{2}$
0.066
$\delta_{1}=\delta_{2}$
$(0.067)$
$-0.080$
t-statistic/F-statistics from 1st Stage
4.46
4.62
5.19
$10.28,24.27$
2. Projection-based Simulated IV
$\delta_{0}$
$0.588^{* *}$
$0.648^{* *}$
$(0.252)$
$\delta_{0}=\delta_{1}$
$(0.200)$
$0.182^{*}$
$(0.092)$
$\delta_{0}=\delta_{1}=\delta_{2}$
0.026
$\delta_{1}=\delta_{2}$
$(0.057)$
$-0.319^{* *}$
$(0.126)$
t-statistic/F-statistics from 1st Stage
5.09
5.82
$12.31,18.63$

B. Achievement Model: $y_{i a}=x_{i}^{\prime} \alpha_{a}+w_{i a}^{\prime} \beta+I_{i a} \delta_{0}+\left(I_{i, a-1}+\ldots+I_{i, 0}\right) \delta_{1}+\mu_{i}+\varepsilon_{i a}$

1. Simulated IV
$\delta_{0}=\delta_{1}$
$-0.108$
$\omega \equiv \delta_{0}-\delta_{1}$
$(0.093)$
$\delta_{1}$
$0.610^{* *}$
$(0.193)$
$-0.049$
t-statistic/F-statistics from 1st Stage
$4.14 \quad 11.82,10.18$

2. Projection-based Simulated IV
$\delta_{0}=\delta_{1}$
0.068
$\omega \equiv \delta_{0}-\delta_{1}$
(0.098)
$\delta_{1}$
$0.815^{* *}$
$(0.381)$
0.201
(0.171)
t-statistic/F-statistics from 1st Stage
2.25
$4.51,3.41$

Notes: Child achievement is a normalized average of math and reading scores. Income is measured in $\$ 10,000$ of year 2000 dollars. All specifications control for 'variables used to predict earnings' and 'other baseline variables' listed in Appendix Table B1 and are estimated in two-year differences to account for unobserved child fixed effects. SIV also includes a sixth order polynomial in lagged pre-tax income. Panel A estimates restricted versions of equation (2) and panel B estimates equation (5) in the paper. t-statistic/F-statistics are for SIV or PSIV instruments in first-stage equation. Sample size is 9,021 for all SIV specifications and 9,019 for all PSIV specifications. Standard errors are reported in parentheses and are clustered at the family level. **Significant at the $5 \%$ level, * significant at the $10 \%$ level. 
Table 6. SIV and PSIV Estimates of 'Contemporaneous Effects Model' for Various Subgroups

\begin{tabular}{|c|c|c|c|c|}
\hline & \multicolumn{2}{|c|}{ "Simulated IV } & \multicolumn{2}{|c|}{ Projection-based SIV } \\
\hline & (i) & (ii) & (iii) & (iv) \\
\hline & $\underline{\text { Black or Hispanic }}$ & White (not Hisp.) & $\underline{\text { Black or Hispanic }}$ & White (not Hisp.) \\
\hline Current Income & $\begin{array}{c}0.875^{* *} \\
(0.416)\end{array}$ & $\begin{array}{l}0.376^{*} \\
(0.228)\end{array}$ & $\begin{array}{c}0.714^{* *} \\
(0.250)\end{array}$ & $\begin{array}{l}0.464^{*} \\
(0.252)\end{array}$ \\
\hline t-stat. from 1st Stage & 2.97 & 3.41 & 3.97 & 2.89 \\
\hline \multirow[t]{2}{*}{ Sample Size } & 5,251 & 4,584 & 5,249 & 4,584 \\
\hline & $\frac{\text { High School }}{\underline{\text { or Less }}}$ & $\frac{\text { Some College }}{\underline{\text { or More }}}$ & $\frac{\text { High School }}{\underline{\text { or Less }}}$ & $\frac{\text { Some College }}{\underline{\text { or More }}}$ \\
\hline Current Income & $\begin{array}{c}0.681^{* *} \\
(0.238)\end{array}$ & $\begin{array}{c}0.225 \\
(0.431)\end{array}$ & $\begin{array}{c}0.739^{* *} \\
(0.248)\end{array}$ & $\begin{array}{c}0.188 \\
(0.209)\end{array}$ \\
\hline \multirow[t]{2}{*}{ Sample Size } & $\begin{array}{c}4.54 \\
7,085\end{array}$ & $\begin{array}{c}1.68 \\
2,750\end{array}$ & $\begin{array}{c}4.03 \\
7,083\end{array}$ & $\begin{array}{c}2.95 \\
2,750\end{array}$ \\
\hline & $\underline{\text { Not Married }}$ & $\underline{\text { Married }}$ & $\underline{\text { Not Married }}$ & $\underline{\text { Married }}$ \\
\hline Current Income & $\begin{array}{c}1.065 \\
(0.966)\end{array}$ & $\begin{array}{c}0.487^{* *} \\
(0.195)\end{array}$ & $\begin{array}{l}1.244^{* *} \\
(0.642)\end{array}$ & $\begin{array}{c}0.400 * * \\
(0.166)\end{array}$ \\
\hline \multirow[t]{2}{*}{ Sample Size } & $\begin{array}{c}1.71 \\
3,312\end{array}$ & $\begin{array}{c}4.17 \\
5,798\end{array}$ & $\begin{array}{c}2.55 \\
3,310\end{array}$ & $\begin{array}{c}4.11 \\
5,798\end{array}$ \\
\hline & $\frac{\text { Low Predicted }}{\underline{\text { Income }}}$ & $\frac{\text { High Predicted }}{\underline{\text { Income }}}$ & $\frac{\text { Low Predicted }}{\underline{\text { Income }}}$ & $\frac{\text { High Predicted }}{\underline{\text { Income }}}$ \\
\hline Current Income & $\begin{array}{c}0.602^{* *} \\
(0.300)\end{array}$ & $\begin{array}{l}0.716^{*} \\
(0.373)\end{array}$ & $\begin{array}{l}0.982^{*} \\
(0.434)\end{array}$ & $\begin{array}{c}0.575 * * \\
(0.244)\end{array}$ \\
\hline t-stat. from 1st Stage & 3.78 & 2.50 & 2.75 & 3.16 \\
\hline Sample Size & 4,916 & 4,919 & 4,914 & 4,919 \\
\hline
\end{tabular}

Notes: Income is measured in $\$ 10,000$ of year 2000 dollars. All specifications control for 'variables used to predict earnings' and 'other baseline variables' listed in Appendix Table B1 and are estimated in two-year differences to account for unobserved child fixed effects. t-statistics are for SIV or PSIV instruments in first-stage equation. Standard errors are reported in parentheses and are clustered at the family level. ${ }^{* *}$ Significant at the $5 \%$ level, ${ }^{*}$ significant at the $10 \%$ level. 
Table 7: Estimates of 'Contemporaneous Effects Model' by Test Subject and Age of Child

\begin{tabular}{ccccc}
\hline \hline & Combined Math & Reading & Reading & \\
and Reading & Recognition & Comprehension & Math \\
& (i) & (ii) & (iii) & (iv) \\
\hline
\end{tabular}

A. Simulated IV

$\begin{array}{lcccc}\text { Effect of Current Income } & 0.402^{* *} & 0.016 & 0.575^{* *} & 0.330 \\ & (0.204) & (0.211) & (0.274) & (0.272) \\ \text { Current Income } \times \text { Child Age } \leq 10 & 0.485^{*} & 0.796^{* *} & 0.355 & 0.621^{*} \\ & (0.282) & (0.332) & (0.331) & (0.365) \\ \text { F-statistics from 1st Stage } & 11.1,10.3 & 9.0,10.5 & 11.6,10.8 & 10.5,10.4 \\ & & & & \\ \text { Projection-based Simulated IV } & & & & \\ \text { Effect of Current Income } & 0.495^{* *} & -0.293 & 0.681^{* *} & 0.669^{* *} \\ & (0.233) & (0.248) & (0.315) & (0.313) \\ \text { Current Income } \times \text { Child Age } \leq 10 & 0.244 & 1.136^{* *} & -0.195 & -0.055 \\ & (0.457) & (0.484) & (0.514) & (0.505) \\ \text { F-statistics from 1st Stage } & & & & 12.6,9.0 \\ \end{array}$

Notes: Income is measured in $\$ 10,000$ of year 2000 dollars. All specifications control for 'variables used to predict earnings' and 'other baseline variables' listed in Appendix Table B1 and are estimated in two-year differences to account for unobserved child fixed effects. SIV also includes a sixth order polynomial in lagged pre-tax income. 'Child Age $\leq 10$ ' is an indicator variable equal to one if the child is age 10 or less. F-statistics are for SIV or PSIV instruments in first-stage equations. SIV sample sizes are 12,579 for reading recognition, 9,972 for reading comprehension, 12,728 for math, and 9,835 for the combined math and reading score (a normalized average of both reading and math scores). PSIV sample sizes are 12,575 for reading recognition, 9,970 for reading comprehension, 12,724 for math, and 9,833 for the combined math and reading score. Standard errors are reported in parentheses and are clustered at the family level. **Significant at the $5 \%$ level, *significant at the $10 \%$ level. 
Table 8: Robustness of Estimates for 'Contemporaneous Effects Model'

\begin{tabular}{ccc}
\hline \hline & Simulated IV & (i) \\
Projection-based SIV \\
(ii)
\end{tabular}

A. Controls for Mother's Family Background \& Additional Variables

$\begin{array}{lcc}\text { Effect of Current Income } & 0.850^{* *} & 0.593^{* *} \\ & (0.365) & (0.183) \\ \text { t-statistic from 1st Stage } & 3.19 & 4.71\end{array}$

B. Interact Control Function with all Regressors

Effect of Current Income $\quad 0.603^{* *}$

$(0.223) \quad \mathrm{N} / \mathrm{A}$

t-statistic from 1st Stage $\quad 4.42$

C. Use both State and Federal EITC to Construct Instruments

Effect of Current Income $\quad 0.623^{* *} \quad 0.612^{* *}$

$(0.226) \quad(0.186)$

$\begin{array}{lll}\text { t-stat. from 1st Stage } & 4.35 & 4.82\end{array}$

D. Limit Sample to States with High EITC Takeup Rates

Effect of Current Income $\quad 0.559 \quad 0.783^{* *}$

$(0.342) \quad(0.324)$

$\begin{array}{lll}\text { t-stat. from 1st Stage } & 2.81 & 3.41\end{array}$

E. Log Family Income Measure

Effect of Log Current Income $\quad 0.819^{* *} \quad 0.874^{* *}$

$(0.292) \quad(0.301)$

t-statistic from 1st Stage $\quad 3.75 \quad 3.62$

F. Control for Mother's Labor Market Participation and Work Hours

\begin{tabular}{lcc} 
Effect of Current Income & $0.733^{* *}$ & $0.715^{* *}$ \\
& $(0.276)$ & $(0.232)$ \\
Effect of Mother's Participation & 0.043 & 0.058 \\
& $(0.033)$ & $(0.034)$ \\
Effect of Mother's Work Hours (in 100's) & $-0.013^{* *}$ & $-0.015^{* *}$ \\
& $(0.005)$ & $(0.005)$ \\
t-statistic from 1st Stage & 3.89 & 4.20 \\
\hline
\end{tabular}

Notes: Specifications identical to those for 'Combined Math and Reading' in Table 3 with the noted exceptions. Specification A controls for all variables in Appendix Table B1. Specification B interacts the control function (sixth order polynomial in lagged income) with all baseline regressors (SIV only). Specification C uses both federal and state EITC amounts to construct our SIV and PSIV instruments (controls for baseline regressors and state fixed effects). Specification D limits the sample to the 25 states where estimated EITC filing rates are $84.6 \%$ or higher. Specification E uses log family income rather than income measured in levels (controls for baseline regressors). Specification F controls for mother's labor market participation and hours worked in addition to baseline regressors. Sample sizes are 9,835 (SIV) and 9,833 (PSIV) for Specifications A, B, and C; 3,658 (SIV) and 3,657 (PSIV) for Specification D; 8,318 (SIV) and 9,721 (PSIV) for Specification E; and 9,459 (SIV) and 9,434 (PSIV) for Specification F. Standard errors are reported in parentheses and are clustered at the family level. **Significant at the $5 \%$ level, *significant at the $10 \%$ level. 
Table B1: Sample Characteristics for Children, their Mothers, and their Families

\begin{tabular}{|c|c|c|c|c|}
\hline & $\begin{array}{c}\text { Entire } \\
\text { Sample } \\
\text { (i) }\end{array}$ & $\begin{array}{c}\text { Eligible } \\
\text { for EITC } \\
\text { (ii) } \\
\end{array}$ & $\begin{array}{c}\text { Not Eligible } \\
\text { for EITC } \\
\text { (iii) }\end{array}$ & $\begin{array}{c}\text { Difference } \\
\text { (ii)-(iii) } \\
\text { (iv) }\end{array}$ \\
\hline \multicolumn{5}{|l|}{ A. Variables used to predict pre-tax earnings } \\
\hline mother is black & .35 & .37 & .31 & $0.06^{* *}$ \\
\hline mother is hispanic & .19 & .20 & .18 & $0.02^{*}$ \\
\hline mother is foreign born & .06 & .07 & .06 & 0.01 \\
\hline mother's age & 33.67 & 33.77 & 33.51 & $0.26^{* *}$ \\
\hline mother's age-squared & 1146.44 & 1152.97 & 1135.70 & $17.27^{* *}$ \\
\hline mother lived in rural area (age 14 ) & .22 & .23 & .20 & $0.03^{* *}$ \\
\hline mother's area of residence (age 14) missing & .00 & .00 & .00 & 0.00 \\
\hline mother a high school dropout (age 23 ) & .22 & .22 & .23 & -0.01 \\
\hline mother a high school graduate (age 23) & .51 & .54 & .46 & $0.08^{* *}$ \\
\hline mother attended some college (age 23 ) & .20 & .20 & .21 & -0.01 \\
\hline mother graduated college (age 23 ) & .06 & .04 & .10 & $-0.06^{* *}$ \\
\hline mother's AFQT score (normalized \& age adjusted) & -.46 & -.53 & -.33 & $-0.20 * *$ \\
\hline mother's AFQT score missing & .03 & .03 & .03 & -0.00 \\
\hline \multicolumn{5}{|l|}{ B. Other baseline variables } \\
\hline child is male & .49 & .49 & .48 & 0.01 \\
\hline child's age & 11.23 & 11.33 & 11.07 & $0.26^{* *}$ \\
\hline child's age-squared & 130.47 & 132.58 & 127.0 & $5.58^{* *}$ \\
\hline number of children in household & 3.82 & 3.79 & 3.88 & $-0.09 * *$ \\
\hline mother newly divorced since last interview & .04 & .05 & .02 & $0.03^{* *}$ \\
\hline mother newly married since last interview & .03 & .03 & .03 & 0.00 \\
\hline \multicolumn{5}{|l|}{ C. Mother's family background variables } \\
\hline mother lived with both natural parents at age 14 & .64 & .62 & .68 & $-0.06^{* *}$ \\
\hline mother's father present in household & .03 & .04 & .02 & $0.02^{* *}$ \\
\hline mother's mother present in household & .06 & .07 & .06 & $0.01^{*}$ \\
\hline number of adults in household & 1.84 & 1.82 & 1.87 & $-0.05^{* *}$ \\
\hline highest grade completed by mother's father & 8.45 & 8.21 & 8.83 & $-0.62^{* *}$ \\
\hline $\begin{array}{l}\text { highest grade completed by mother's mother } \\
\text { missing observation indicators: }\end{array}$ & 9.64 & 9.41 & 10.00 & $-0.59^{* *}$ \\
\hline mother lived with both natural parents at age 14 & .00 & .00 & .00 & $0.00^{*}$ \\
\hline mother's father present in household & .00 & .00 & .00 & -0.00 \\
\hline mother's mother present in household & .00 & .00 & .00 & -0.00 \\
\hline number of adults in household missing & .02 & .01 & .02 & $-0.01^{* *}$ \\
\hline highest grade completed by mother's father & .08 & .08 & .08 & -0.00 \\
\hline highest grade completed by mother's mother & .03 & .03 & .03 & -0.00 \\
\hline
\end{tabular}


Table B1 Continued

\begin{tabular}{lcccc}
\hline \hline & $\begin{array}{c}\text { Entire } \\
\text { Sample } \\
\text { (i) }\end{array}$ & $\begin{array}{c}\text { Eligible } \\
\text { for EITC } \\
\text { (ii) }\end{array}$ & $\begin{array}{c}\text { Not Eligible } \\
\text { for EITC } \\
\text { (iii) }\end{array}$ & $\begin{array}{c}\text { Difference } \\
\text { (ii)-(iii) } \\
\text { (iv) }\end{array}$ \\
\hline D. Additional variables & & & & \\
mother married last year & & & & .67 \\
mother's spouse a high school dropout & .16 & .21 & .09 & $-0.10^{* *}$ \\
mother's spouse a high school graduate & .48 & .52 & .44 & $0.12^{* *}$ \\
mother's spouse attended some college & .20 & .19 & .22 & $-0.08^{* *}$ \\
mother's spouse a college graduate & .15 & .08 & .26 & $-0.18^{* *}$ \\
age of mother's spouse & 34.47 & 33.31 & 36.09 & $-2.78^{* *}$ \\
age of mother's spouse squared & 1293.58 & 1241.99 & 1365.76 & $-123.78^{* *}$ \\
spouse information missing & .00 & .01 & .00 & $0.00^{* *}$ \\
& & & & \\
number of child-year observations & 11,210 & 6,968 & 4,242 & \\
number of children & 4,720 & 3,497 & 2,330 & \\
\hline \hline
\end{tabular}

Notes: Data are from the Children of the NLSY linked to their mothers in the main NLSY79. The unit of observation is a child-year, where a child and his or her parents can appear repeatedly in the sample. The sample is restricted to those used in our SIV analysis. Children must have valid math and reading PIAT scores, family background measures, and family income measures in a year to be included as an observation. Children must also have at least two years of valid observations to be included. Average spousal education and age are reported for the sample of married mothers (sample sizes are $6,864,4,003$, and 2,861 for columns (i) to (iii), respectively. In column (iv), ** denotes statistical significance at $5 \%$ level, and $*$ denotes statistical significance at $10 \%$ level. 